San Jose State University

SJSU ScholarWorks

Master's Theses

Master's Theses and Graduate Research

Fall 2019

\title{
The Effects of a 6-Week Group Meal Prep Program on the Frequency of Consumption of Home-Cooked Meals
}

Shannon Mendez

San Jose State University

Follow this and additional works at: https://scholarworks.sjsu.edu/etd_theses

\section{Recommended Citation}

Mendez, Shannon, "The Effects of a 6-Week Group Meal Prep Program on the Frequency of Consumption of Home-Cooked Meals" (2019). Master's Theses. 5073.

DOI: https://doi.org/10.31979/etd.kte4-bvrk

https://scholarworks.sjsu.edu/etd_theses/5073

This Thesis is brought to you for free and open access by the Master's Theses and Graduate Research at SJSU ScholarWorks. It has been accepted for inclusion in Master's Theses by an authorized administrator of SJSU ScholarWorks. For more information, please contact scholarworks@sjsu.edu. 
THE EFFECTS OF A 6-WEEK GROUP MEAL PREP PROGRAM ON THE FREQUENCY OF CONSUMPTION OF HOME-COOKED MEALS

\author{
A Thesis \\ Presented to \\ The Faculty of the Department of Nutrition, Food Science and Packaging \\ San José State University \\ In Partial Fulfillment \\ of the Requirements for the Degree \\ Master of Science \\ by \\ Shannon Mendez
}

December 2019 
(C) 2019

Shannon Mendez

\section{ALL RIGHTS RESERVED}


The Designated Thesis Committee Approved the Thesis Titled

THE EFFECTS OF A 6-WEEK GROUP MEAL PREP PROGRAM ON THE FREQUENCY OF CONSUMPTION OF HOME-COOKED MEALS

\author{
by
}

Shannon Mendez

\title{
APPROVED FOR THE DEPARTMENT OF NUTRITION, FOOD SCIENCE, AND PACKAGING
}

\section{SAN JOSÉ STATE UNIVERSITY}

December 2019

John Gieng, PhD

Jamie Kubota, MS, RD

Adrianne Widaman, $\mathrm{PhD}$, RD
Department of Nutrition, Food Science \& Packaging, San José State University

Department of Nutrition, Food Science \& Packaging, San José State University

Department of Nutrition, Food Science \& Packaging, San José State University 


\title{
ABSTRACT \\ THE EFFECTS OF A 6-WEEK GROUP MEAL PREP PROGRAM ON THE FREQUENCY OF CONSUMPTION OF HOME-COOKED MEALS
}

\author{
by Shannon Mendez
}

Consumption of food away from home is associated with higher caloric intake and poorer diet quality compared to home-cooked food. The advance quantity meal prep (AQMP) program is a group-based program developed to increase the frequency of consumption of home-cooked meals. The AQMP pilot study was a pre-experimental 6week intervention aimed at analyzing the effects of the program on frequency of consumption of home-cooked meals, cooking attitudes, cooking self-efficacy, and anthropometric measures. Ten study participants met once a week at a commercial kitchen to prepare and package lunches, dinners, and snacks for the work week. A survey was administered and anthropometric measurements were taken at three time points: preprogram, immediately post-program, and 3 months post-program. The questionnaire measured: physical activity, cooking attitudes, cooking self-efficacy, and cooking behavior and consumption. Significant increases were seen in total cooking attitudes $(\mathrm{P}=0.02)$, cooking self-efficacy $(\mathrm{P}=0.002)$, and percentage of home-cooked dinner consumption $(\mathrm{P}=0.04)$. Significant decreases in weight $(\mathrm{P}=0.03)$, body fat mass $(\mathrm{P}=0.01)$, and $\mathrm{BMI}(\mathrm{P}=0.03)$ were reported. The present pilot study indicates that advance quantity meal prep may contribute to increased cooking attitudes, cooking self-efficacy, and consumption of home-cooked dinners. Reduced weight, body fat, and BMI may also be a benefit of the AQMP program. Comparison to a control group would strengthen our conclusions. 


\section{ACKNOWLEDGMENTS}

Graduate school has been one of the most challenging, yet rewarding experiences of my life. This entire process has humbled and stretched me in ways I never thought imaginable. I am very proud of this accomplishment, however it would have never been achievable without the help and support of some very important people. First, my loving, supportive, and patient husband. Thank you Steve Mendez for always encouraging me and cheering me on. I am forever grateful to you for your unwavering support through this journey. Thank you to my advisors, Jamie Kubota, Dr. Adrianne Widaman, and especially Dr. John Gieng. You truly went above and beyond to guide me through this process and ensure I completed it in a timely manner. Thank you for being so generous with your time and energy. It has been an honor to learn from each of you. Thank you to Hsin Yi Tseng for all your help with data collection and helping to make my intervention run smoothly. Your help was greatly appreciated. Finally, thank you to my parents Scott and Mary Ann Taylor. You taught Leslie and I that anything is achievable if you are willing to work hard for it. I hope that we have made you proud with our scholastic and professional accomplishments. 


\section{TABLE OF CONTENTS}

List of Tables........................................................ vii

List of Figures................................................. viii

List of Abbreviations.............................................. ix

CHAPTER 1: Literature Review...................................

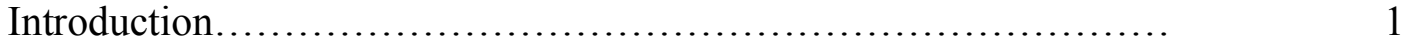

Definitions of Food Sources.................................... 2

The Effects of Eating Food Away From Home....................... 3

Home-Cooked Meals and Health Outcomes.......................... 4

Barriers to Home Cooking....................................... 6

Effectiveness of Group-Based Nutrition Education Interventions...... 9

Framework for Behavioral Change.............................. 11

Conclusion................................................ 13

CHAPTER 2: Journal Article.............................................

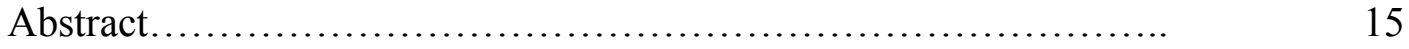

Introduction.................................................. 16

Methods..................................................

Results.................................................. 22

Discussion................................................. 26

Implications for Research and Practice.......................... $\quad 30$

References................................................ 31

CHAPTER 3: Summary and Recommendations......................... 33

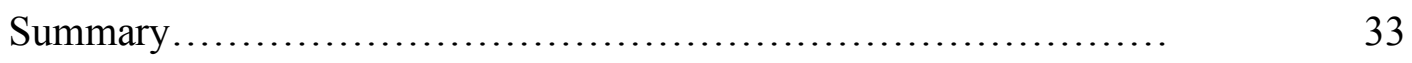

Recommendations..........................................

References.................................................. 35

Appendices.

A. IRB Approval Letter...................................... 39

B. Consent Letter............................................... 40

C. Survey...................................................... 45

D. Email and Social Media Recruitment Script and Flyer.............. 55

E. AQMP Recipes.......................................... 57 


\section{LIST OF TABLES}

Table 1. Nutrition Information for AQMP Meals..................... 19

Table 2. Changes in Anthropometric Data Between Pre-Program, PostProgram, and 3 Months Post-Program...................................

Table 3. Average Total Cooking Attitudes and Self-Efficacy

Scores..................................................

Table 4. $\quad$ ASA Dietary Recall Submissions Per Participant.................

Table 5. Energy Intake and Expenditure of Participants Pre-Program, Post-Program, and 3 Months Post-Program................ 


\section{LIST OF FIGURES}

Figure 1. Average home-cooked meal consumption per week......... 24

Figure 2. $\quad$ Percent home-cooked meal consumption................. 25 


\section{LIST OF ABBREVIATIONS}

AQMP_Advance Quantity Meal Prep

BMI-Body Mass Index

CWC_-Cooking with a Chef

FAH-Food at home

FAFH - Food away from home

HBM-Health Belief Model

HEI-2010 - Healthy Eating Index 


\section{Chapter One}

\section{Literature Review}

\section{Introduction}

Obesity is one of the largest epidemics of modern times, and has been linked with several non-communicable diseases such as Type 2 Diabetes and heart disease (Expert, 2014). In the United States, the prevalence of overweight and obesity has steadily risen over the past several decades. Between 1999-2016, obesity rates rose from $30.5 \%$ to 39.8\% among adults ages 20 and older (Hales, Carroll, Fryar, \& Ogden, 2017). Many factors have led to this increase, one of which is the overabundance and availability of convenience foods, and another the decline in cooking skills and nutrition knowledge (Levy \& Auld, 2004; Saksena et al., 2018).

Food away from home (FAFH) includes food from fast-food establishments and full service restaurants, and is found to have poorer nutritional quality compared to food prepared at home (FAH) (Saksena et al., 2018). FAFH generally contains more calories, is served in larger portion sizes, and is less nutritious (e.g., high in fat and sodium) than FAH (Guthrie et al., 2002; Mancino et al., 2010; Nielsen \& Popkin, 2003). This increase in caloric intake due to higher consumption of FAFH has contributed to weight gain in the US population (Mancino et al., 2010). Studies show that eating home-cooked meals more frequently is associated with lower BMI and body fat percentage, and an overall healthier diet (Mills, Brown, Wrieden, White, \& Adams, 2017; Tiwari, Aggarwal, Tang, \& Drewnowski, 2017; Wolfson \& Bleich, 2014). However, lack of time, nutrition 
knowledge, and cooking skills are reported as powerful deterrents to cooking at home (Tiwari, et al., 2017).

Effective interventions include hands on cooking classes, nutrition education programs, and group classes focused on menu plans, portion control, and food budgeting (Herbert et al., 2014; Jordan, et al., 2008; Keller, Amie Gibbs, Wong, Vanderkooy \& Hedley, 2004; Warmin, Sharp, \& Condrasky, 2012). These interventions have been shown to increase cooking skills, increase confidence with meal preparation, and reduce expenditure on takeaway or fast foods (Herbert et al., 2014; Jordan, et al., 2008; Keller, et al., 2004; Warmin, et al., 2012). Although many studies have addressed cooking skills, cooking attitudes and behaviors, and cooking self-efficacy, there is limited research on programs or methods that promote FAH while addressing time constraints. This literature review examines FAFH and FAH consumption and health, barriers to home cooking, the effectiveness of group-based nutrition education interventions, and a framework for behavioral change.

\section{Definitions of Food Sources}

For this review, food sources are classified into two main categories, defined by where the food was purchased. These categories are defined below:

Food from supermarkets, smaller grocery stores, supercenters, or other retailers is defined as food prepared at home (FAH) although it could include prepared or semi-prepared items such as rotisserie chicken or bagged salad. Food prepared away from home (FAFH) includes foods obtained from full-service restaurants with wait staff, fast-food establishments with no wait staff, food obtained at school or day care, and a catchall "other" subcategory that includes vending machines, common coffee pot/snack tray, Meals on Wheels, street vendor, etc. The definitions of FAH and FAFH are anchored on where the food was obtained. FAH food can be eaten away from home and FAFH food can be eaten at home. For example, FAH includes breads and peanut butter purchased at grocery 
stores and eaten as a peanut butter sandwich at home, school, or work. Meanwhile, home delivery or takeout from a pizza parlor is classified as FAFH even if it is eaten at home. (Saksena et al., 2018)

\section{The Effects of Eating Food Away From Home (FAFH)}

The restaurant industry in the United States has grown from $\$ 43$ billion in 1970 to a projected \$863 billion in 2019 (National Restaurant Association, 2019). Over the years, many home-cooked meals have been replaced by restaurants, fast food, delivery, and ready-made meals (Guthrie et al., 2002; Mancino et al., 2010; Nielsen \& Popkin, 2003; Saksena et al., 2018). Between 1987 and 2017 FAFH expenditure rose steadily. In 2010, for the first time in history, FAFH exceeded FAH expenditure, accounting for about 50.2 percent of total U.S. food spending for that year (Saksena et al., 2018). Between 1965 and 2008, the proportion of daily energy consumed from home food sources decreased by approximately 23 percent (Smith, $\mathrm{Ng}$, and Popkin, 2013). In addition, the average American's energy intake from FAFH consumption doubled from 17 percent in 1977-78 to 34 percent in 2013-14 (Saksena et al., 2018).

Simultaneously, obesity rates steadily increased. Many studies have shown that consumption of FAFH is associated with poor diet quality (Harnack et al., 2000; Lachat et al., 2012; Saksena et al., 2018; Tiwari et al., 2017; Todd, Mancino, \& Lin, 2010). One study found that people eat more calories overall and have poorer diet quality on days when they eat at least one meal away from home, with the greatest effect being the reduction in the number of servings of fruits, vegetables, whole grains, and dairy (Todd et al., 2010). Similar studies showed higher frequency of eating FAFH was associated with significantly poorer diet quality scores and was associated with higher total energy 
intake, higher total fat intake, and lower micronutrient intake (Lachat et al., 2012; Tiwari et al., 2017). In general, FAFH contains more saturated fats and sodium, and less calcium, iron and fiber than FAH does (Saksena et al., 2018).

Furthermore, findings from many research studies show a positive correlation between frequency of fast food consumption and BMI (Bhutani, Schoeller, Walsh, \& McWilliams, 2018; Duffey, Gordon-Larsen, Steffen, Jacobs Jr, \& Popkin, 2009; Fulkerson et al., 2011; Gillis \& Bar-Or, 2003). Fast food, in particular, is associated with high energy intake, low intake of essential micronutrients, and inferior metabolic outcomes (Duffey et al., 2009; Fulkerson et al., 2011; Gillis \& Bar-Or, 2003). In a study of metropolitan communities in Wisconsin, it was found that for every 1 meal per week increase in fastfood and sit-down restaurant consumption, BMI increases by 0.8 and $0.6 \mathrm{~kg} / \mathrm{m}$, respectively (Bhutani et al., 2018).

The shift in consumer preferences toward FAFH does not come without a price, however. The prevalence of obesity and non-communicable diseases such as diabetes, heart disease, and some cancers continues to rise in America, and poor diet quality is a major contributing factor to this problem (Expert, 2014).

\section{Home-Cooked Meals and Health Outcomes}

Research shows that an increased frequency of consuming FAH is associated with a healthier diet, lower BMI and body fat, and improved cardio-metabolic markers (Mills et al., 2017; Tiwari et al., 2017; Wolfson \& Bleich, 2014). In a cross-sectional analysis of a population-based cohort, more frequent consumption of FAH was correlated with greater likelihood of having normal range BMI and body fat percentage, improved cardio- 
metabolic markers, and better overall diet quality (Mills et al., 2017). Those consuming FAH more than five times per week, compared with less than three times per week, were $28 \%$ less likely to have overweight BMI, $24 \%$ less likely to have excess percentage body fat, and consumed significantly more fruits and vegetables (Mills et al., 2017). In addition, a higher frequency of consuming home-cooked meals was associated with markers of improved cardio-metabolic health, including lower risk cholesterol ratio and lower risk of diabetes according to HbAlc level (Mills et al., 2017).

Using the Healthy Eating Index (HEI-2010) to assess diet quality through compliance with the Dietary Guidelines for Americans, 2010 (USDA, 2011), a primary data collection study of food environment, diets and health observed that the HEI-2010 score increased as the frequency of cooking dinner at home increased (Tiwari et al., 2017). HEI- 2010 is based on scores for 12 dietary components: total fruit, whole fruit, total vegetables, greens and beans, whole grains, dairy, total protein foods, seafood and plant proteins, fatty acids, refined grains, sodium, and empty calories (Guenther et al., 2013). HEI scores range from 0 to 100 , with higher scores indicating better diet quality. HEI scores $>80$ indicate a "good" diet, scores ranging from 51 to 80 reflect a diet that "needs improvement," and HEI scores <51 imply a "poor" diet. In this study, the group who cooked dinner at home six or more times per week had a 7 point increase in HEI2010 score compared to those who cooked dinner at home zero to three times per week (Tiwari et al., 2017). Of the HEI component subcategories, the empty calorie HEI subscore had the strongest results between cooking at home and eating outside the home, 
indicating that more frequent home cooking is linked to consumption of fewer empty calories (Tiwari et al., 2017).

Similarly, another observational study used the consumer behavior module of the National Health and Nutrition Examination Survey (NHANES) to examine the association between cooking frequency and diet quality. In accordance to key goals of the 2010 Dietary Guidelines of America (USDA, 2011), this study considered lower overall energy, carbohydrate, fat, and sugar intake to be healthier or improved diet quality (Wolfson \& Bleich, 2014). They found that people that eat dinner more frequently at home had better overall diet quality, specifically lower total energy consumption, lower carbohydrate, fat and sugar consumption, and lower consumption of convenience foods (Wolfson \& Bleich, 2014).

As the current body of research demonstrates, greater consumption of FAH increases diet quality, promotes a healthy BMI and body fat percentage, and improves cardiometabolic markers. Hence, home meal preparation and consumption has been increasingly promoted by researchers as a strategy for improving dietary quality and preventing obesity (Mills et al., 2017; Smith et al., 2013; Wolfson \& Bleich, 2014).

\section{Barriers to Home Cooking}

Eating patterns of Americans have changed dramatically over the past few decades, leading to over half the US population becoming overweight or obese (Expert, 2014; Saksena et al., 2018). Many studies and programs have sought to solve the problem of obesity. What has been found is that this is a multifaceted issue that deals with physiological, psychological and behavioral matters. Many barriers to home cooking 
including perceived time constraints, competing priorities, social and peer pressure, and lack of desire to cook, have been identified in previous research (Macdiarmid, Loe, Kyle, and McNeill, 2013; Pelletier, \& Laska, 2012).

Over the past century, the development of industry, changes in the job market, attitudes toward family, and how people spend leisure time have shaped food preferences and eating routines (Harris \& Shiptsova, 2007; Saksena et al., 2018). Rising incomes, more dual-income households, and improved affordability and access to fast food may have all contributed to growing FAFH demand (Harris \& Shiptsova, 2007; Saksena et al., 2018; Smith et al., 2013). As time constraints became greater, due in part to higher educational attainment and increases in women's participation in the labor force, less time was dedicated to meal preparation, causing a decline in FAH (Saksena et al., 2018; Smith et al., 2013).

An observational study that analyzed US dietary surveys found that from 1965 to 2007 , the proportion of women who cook decreased by $24.6 \%$. In $1965,92.3 \%$ of females cooked and spent 112.8 minutes per day preparing food. By 2007, these numbers dropped to $67.7 \%$ and 65.6 minutes respectively (Smith et al., 2013). This downturn in time spent cooking has created a decline in cooking skills and desire to cook and is causing a gap in intergenerational transmission of cooking knowledge and skills (Lang \& Caraher, 2001). Children are less likely to acquire the basic cooking skills once taught by their parents or at school (Wolfson, Frattaroli, Bleich, Smith, \& Teret, 2017). The result is a decrease in young adults who possess the cooking skills necessary to prepare meals from scratch or partly from scratch (Levy \& Auld, 2004). For American 
families, this research may indicate that preparing healthy meals has become less of a priority, contributing to an increase in consumption of convenience foods, which are traditionally calorie dense and nutrient deficient.

In a study designed to identify barriers to healthy eating and sustainable dietary change, it was found that competing priorities, such as work patterns, family commitments and activities, and time constraints were common barriers to eating a healthy diet (Macdiarmid et al., 2013). Shopping, preparing, and eating healthy meals was described as problematic due to lack of time, as healthy eating tended to be associated with cooking meals from scratch, which was seen as time-consuming. Work patterns such as shift work, irregular hours, and getting home late at night also contributed to an unhealthy diet (Macdiarmid et al., 2013). Another study evaluating barriers to healthy eating and physical activity in a workplace weight management intervention found that lack of self-control and convenience were the greatest barriers to healthy eating (Stankevitz et al., 2017). Furthermore, a study of young adults found that male college students with a heavier course and/or workload had higher perceived time constraints affecting dietary behaviors. Whereas female college students with more family responsibilities had higher perceived time constraints affecting dietary behaviors. Although for different reasons, in both cases, as the perceived time constraints increased, healthy dietary behaviors declined (Pelletier \& Laska, 2012). All of these studies indicate that promoting healthy meals with short preparation time could be valuable and utilized by "busy" people (Macdiarmid et al., 2013; Pelletier \& Laska, 2012; Stankevitz et al., 2017). 


\section{Effectiveness of Group-Based Nutrition Education Interventions}

Group-based nutrition education programs are another approach that have been used to overcome barriers to healthy home cooking. Many of these programs use a hands-on approach, utilizing strategies for supporting people to learn to cook healthy meals (Flego et al., 2014; Herbert et al., 2014; Keller, Gibbs, Wong, Vanderkooy, \& Hedley, 2004; Warmin et al., 2012). Group-based programs also add a social element, which is designed to create a fun and interactive learning environment.

Jamie's Ministry of Food 10-week community-based cooking skills program, and the Cooking with a Chef (CWC) program are two hands-on cooking interventions designed to teach participants how to prepare and cook a variety of dishes, while fostering selfefficacy and long-term behavioral change regarding healthy nutrition (Flego et al., 2014; Herbert et al., 2014; Warmin et al., 2012).

Jamie's Ministry of Food Program showed statistically significant increases in cooking confidence measures, vegetable intake, and cooking from basic ingredients (Flego et al., 2014). The program has also been shown to improve attitudes, beliefs, knowledge, and enjoyment around cooking and healthy eating, which in turn enabled participants to improve cooking and meal practices at home (Herbert et al., 2014). A unique and important aspect of this study design was the 6-month post-program follow up survey. Statistically significant increases were sustained in the intervention group, which indicates long-term behavior change (Flego et al., 2014).

Using a validated survey instrument, CWC results showed significant increases in Cooking Self-Efficacy (SEC), Self-Efficacy for Using Basic Cooking Techniques 
(SECT), Self-Efficacy for Fruits, Vegetables, and Seasonings (SEFVS), and Knowledge of Cooking Terms and Techniques. The CWC program was found to be an effective means of delivering culinary and nutrition information and could be a viable strategy for improving college students' diets by developing cooking skills, confidence and healthier food choices (Warmin et al., 2012).

The Senior Men's Cooking Group, a community-based nutrition intervention, sought to increase confidence in cooking, increase cooking meals at home from scratch, and increase pleasure and satisfaction from producing and consuming meals made from scratch. The men involved in the group met once a month for 8 months to prepare and consume a meal together. In the end, the majority of participants gained cooking confidence, increased their cooking activities at home, developed healthy cooking skills, and improved cooking variety through the program (Keller et al., 2004).

Group-based nutrition education programs have been shown to increase cooking confidence, skills, knowledge, variety, and fruit and vegetable consumption (Flego et al., 2014; Herbert et al., 2014; Keller et al., 2004; Warmin et al., 2012). The results of these studies suggest that the development and further research of group-based nutrition education programs could be beneficial for promoting FAH (Flego et al., 2014; Herbert et al., 2014; Keller et al., 2004; Warmin et al, 2012). Successful strategies to develop confidence, skills, and desire to cook are needed to increase the diet quality of the US population. The belief is, if diet quality can be increased, then the prevalence of obesity and obesity-related diseases would decrease. Many studies show the positive effects that home cooking has on diet quality (Mills et al., 2017; Smith et al., 2013; Wolfson \& 
Bleich, 2014), however, currently there are a limited number of studies that examine the link between culinary classes aimed at healthy cooking and subsequent changes in FAH consumption. One study, nevertheless, does show that increasing cooking skills could lead to an increase in cooking frequency (Levy \& Auld, 2004). This is a promising direction for future research.

\section{Framework for Behavioral Change}

The psychology behind food and meal preparation continues to be an area of interest for many researchers. In her article, Costa (2013), sought to conceptualize and measure the personal norms regarding meal preparation. She found that many consumers still feel a sense of duty to cook household meals on a daily basis, even though studies consistently highlight the central role of convenience in everyday food choices (Harris \& Shiptsova, 2007; Saksena et al., 2018; Smith et al., 2013). Feelings of guilt and other negative emotions arise when considering resorting to the use of alternatives such as ready-made meals. Consumers have strong positive beliefs about the effects of cooking hot meals every day, and equally strong negative beliefs about regular use of alternative meal replacements (Costa, 2013). Previous research shows that theory provides a strong foundation for interventions designed to promote healthy eating and building new habits (Michaund, 2007).

The Health Belief Model (HBM) is a psychological health behavior change model that consists of six constructs: perceived susceptibility, perceived severity, perceived benefits, perceived barriers, cues to action, and self-efficacy (Becker, 1974). This theory suggests that for a change in nutrition behavior to occur, the perceived benefits must outweigh the 
perceived costs. This model can be used to guide health promotion and disease prevention programs (Becker, 1974). In a Florida study, the HBM was used for a nutrition education intervention with University staff. A treatment group participated in eight 1-hour weekly nutrition education sessions in which the constructs of the HBM were integrated. The results showed an increase in perceived benefits regarding the adoption of positive dietary behaviors, nutrition knowledge significantly increased, and total energy, fat, saturated fat, and cholesterol were significantly reduced by the end of the 8-week intervention (Abood, Black, \& Feral, 2003).

Self-efficacy is the belief that one can carry out the behavior necessary to reach a desired goal, and in doing so obtain a projected outcome. The subject also gains selfconfidence in his or her own ability. Self-efficacy is one of the constructs of HBM that is of particular importance in nutritional behavioral change. A major premise behind selfefficacious behavior is that if the behavior produces the desired result, the behavior is more likely to be repeated (Jackson, Tucker, \& Herman, 2007). The degree of selfefficacy can both result from a specific behavior and predict future frequencies of that behavior (Clark \& Dodge, 1999; Jackson et al., 2007). Two studies mentioned earlier, Jamie's Ministry of Food Program and the Cooking with a Chef program, reported significant increases in cooking self-efficacy among study participants, with Jamie's Ministry of Food participants sustaining the results 6 months after the intervention (Flego et al., 2014; Warmin et al., 2012). As researchers continue to create relevant studies regarding nutrition in the US, it is important to utilize theory-based methods in order to promote new, long-term nutrition habits. 


\section{Conclusion}

This review has demonstrated the effects of FAFH, health outcomes associated with eating FAH more frequently, barriers to home cooking, and the effectiveness of groupbased nutrition education interventions. The evidence shows that increased frequency of FAH is associated with a healthier diet, lower BMI and body fat, and more favorable biomarkers (Bhutani et al., 2018; Mills et al., 2017; Tiwari et al., 2017; Wolfson \& Bleich, 2014). However, many barriers to home cooking exist such as lack of time, desire, cooking skills and competing priorities (Macdiarmid et al., 2012; Pelletier \& Laska, 2012; Smith et al., 2014). Strategies such as meal planning and group-based nutrition education programs have been created to increase nutrition knowledge, cooking skills, and the frequency of home cooking (Ducort et al., 2017; Flego et al., 2014, Herbert et al., 2014; Keller et al., 2004; Warmin et al., 2012). Some success has been demonstrated, however, in order to overcome the barrier of perceived time constraint, much more innovation is needed in this area. In summary, as the US population has moved away from home cooking more and more over the past five decades, the prevalence of obesity has steadily risen (Expert, 2014; Saksena et al., 2018). One possible strategy to reverse this pattern is to return to cooking and eating home-cooked meals most of the time. This may prove easier said than done, as behavioral changes must be made in order for new, long-term habits to be created. 


\section{CHAPTER 2}

THE EFFECTS OF A 6-WEEK GROUP MEAL PREP PROGRAM ON THE FREQUENCY OF CONSUMPTION OF HOME-COOKED MEALS 


\begin{abstract}
Objective: To analyze the effects of a 6-week group-based advance quantity meal prep (AQMP) program on the frequency of consumption of home-cooked meals, cooking attitudes, self-efficacy, and anthropometric measures.
\end{abstract}

Methods: A pre-experimental research design was used. A survey was administered and anthropometric measurements were taken at three time points: pre-program, postprogram, and 3 months post-program. The questionnaire measured physical activity, cooking attitudes, cooking self-efficacy, and cooking behavior and consumption.

Results: Significant increases were seen in total cooking attitudes $(\mathrm{P}=0.01)$, cooking selfefficacy $(\mathrm{P}=0.002)$, and percentage of home-cooked dinner consumption $(\mathrm{P}=0.04)$. Significant decreases in weight, body fat mass, and BMI were reported.

Conclusions and Implications: The present pilot study indicates that AQMP may contribute to increased cooking attitudes, cooking self-efficacy, and consumption of home-cooked dinners. Reduced weight, body fat, and BMI may also be a benefit of the AQMP program. Comparison to a control group would strengthen our conclusions. 


\section{INTRODUCTION}

Obesity is one of the largest epidemics of modern times, and has been linked with several non-communicable diseases such as Type 2 Diabetes and heart disease. ${ }^{1}$ In the United States, the prevalence of overweight and obesity has steadily risen over the past several decades. ${ }^{2}$ Many factors such as the overabundance and availability of convenience foods, an increase in consumption of calorically dense food from sources outside the home, and the decline in cooking skills and nutrition knowledge have contributed to this increase. ${ }^{1,3,4}$ Studies show that eating home-cooked meals more frequently is associated with lower body mass index (BMI) and body fat percentage, and an overall healthier diet. ${ }^{5-7}$ However, lack of time, nutrition knowledge, and cooking skills are reported as barriers to cooking at home. ${ }^{6}$ Effective interventions to overcome these barriers include hands-on cooking classes, nutrition education programs, and group classes focused on menu plans, portion control, and food budgeting. ${ }^{8-11}$ These interventions were shown to increase cooking skills, increase confidence with meal preparation, and reduce financial expenditure on takeaways or fast foods. ${ }^{8-11}$ Although many studies have evaluated cooking skills, cooking attitudes and behaviors, and cooking self-efficacy, there is limited research on programs or interventions that promote homecooked meal preparation and consumption, while addressing time constraints.

Advance quantity meal prep (AQMP) is a term created by the authors to describe the process of planning and preparing meals in bulk, ahead of time, to eat at a later date. The AQMP program is a 6-week group-based program ${ }^{8,10,11,20}$ designed to increase consumption of home-cooked meals, increase cooking self-efficacy, and promote positive 
and healthy cooking attitudes and behaviors. We hypothesize that an AQMP program can reduce barriers to consuming home-cooked meals, which will in turn increase the frequency of home-cooked meals consumption and, therefore, improve BMI and body fat outcomes. The primary aim of this study was to determine if the 6-week group AQMP program increases the frequency of consumption of home-cooked meals in healthy adults; the secondary aims were to determine if the program improves anthropometric measurements, cooking attitudes, and cooking self-efficacy. The goal of this program is the long-term adoption of healthy behaviors and to maintain a high frequency of consumption of home-cooked meals, which in turn may positively affect health outcomes.

\section{METHODS}

\section{Study design}

The AQMP program was tested in a pre-experimental pilot study on healthy adult members of a fitness center in Santa Clara, CA, in early 2019. The AQMP program was developed to focus on several constructs of the Health Belief Model (HBM), specifically, perceived barriers, perceived benefits, and self-efficacy. The HBM offers a theory-based approach for behavior change in regards to nutrition ${ }^{12}$ and provides an applicable framework for efficient food preparation and healthy eating. The AQMP program addresses the barrier of perceived time constraints, which is one of the most widely reported barriers to home-cooked meal consumption. ${ }^{13,14}$ This program also addresses the benefits of home-cooked meal consumption such as diet quality and weight and body 
fat management. Self-efficacy was developed by allowing the participants to practice new cooking skills each week in a fun and supportive environment.

Participants met for 6 consecutive Sundays from $8 \mathrm{am}-12 \mathrm{pm}$ at a commercial kitchen. Collectively, the participants prepared, cooked, and packaged 5 lunches, 5 dinners, and 5 snack packs for each participant each week. The menus, recipes, and ingredients were determined and acquired by the program facilitator prior to each meeting. Recipes were developed based on a nutritionally balanced plate with emphasis on lean meats, whole grains, and fruits and vegetables, in addition to low sugar, sodium and saturated fat, in accordance with the Dietary Guidelines for Americans, 2010. ${ }^{15}$ For variety, three different dishes were prepared by the group each week. For example, one week included a chicken dish, a turkey dish and a beef dish. The participants received 4 chicken meals, 3 turkey meals, and 3 beef meals; it was suggested to the participants that the 10 meals be consumed for lunch and dinner during the work week, however no strict guidelines were given for the intervention.

Table 1 shows the nutrition information for each meal and snack prepared during the study. Each meal was individually packaged in a reusable plastic container and the participants were instructed to take the meals home and refrigerate them until they were consumed. During the program, each participant was assigned several preparation and cooking tasks each week to develop cooking skills and confidence. Some tasks include chopping vegetables, trimming and baking chicken breasts, preparing brown rice, and roasting potatoes. Research staff provided cooking education one-on-one to participants, 
as needed. Cooking education included verbal instructions, demonstrations, and time saving techniques. Participants also shared knowledge and cooking tips with each other.

In order to determine if the AQMP program increased the consumption of homecooked meals, the participants were assessed at 3 time points during the study: preprogram (T1), post-program (T2) and 3 months post-program (T3).

\begin{tabular}{|c|c|c|c|c|c|c|}
\hline & Meal & $\begin{array}{c}\text { Energy } \\
\text { (kcal) }\end{array}$ & $\begin{array}{l}\text { Fat } \\
\text { (g) }\end{array}$ & $\begin{array}{c}\text { CHO } \\
\text { (g) }\end{array}$ & $\begin{array}{l}\text { Protein } \\
\text { (g) }\end{array}$ & $\begin{array}{l}\text { Dietary Fiber } \\
\text { (g) }\end{array}$ \\
\hline \multirow{4}{*}{ Week 1} & 1 & 940 & 41 & 80 & 54 & 10 \\
\hline & 2 & 792 & 29 & 77 & 58 & 14 \\
\hline & 3 & 704 & 34 & 72 & 28 & 8 \\
\hline & snack & 396 & 24 & 35 & 15 & 6 \\
\hline \multirow{4}{*}{ Week 2} & 1 & 670 & 40 & 47 & 33 & 5 \\
\hline & 2 & 549 & 33 & 41 & 26 & 6 \\
\hline & 3 & 631 & 22 & 46 & 61 & 5 \\
\hline & snack & 396 & 24 & 35 & 15 & 6 \\
\hline \multirow{4}{*}{ Week 3} & 1 & 804 & 24 & 82 & 63 & 11 \\
\hline & 2 & 483 & 20 & 35 & 44 & 8 \\
\hline & 3 & 508 & 11 & 79 & 24 & 10 \\
\hline & snack & 396 & 24 & 35 & 15 & 6 \\
\hline \multirow{4}{*}{ Week 4} & 1 & 708 & 29 & 69 & 48 & 12 \\
\hline & 2 & 552 & 30 & 41 & 31 & 8 \\
\hline & 3 & 681 & 21 & 69 & 57 & 7 \\
\hline & snack & 374 & 24 & 29 & 15 & 5 \\
\hline \multirow{4}{*}{ Week 5} & 1 & 804 & 39 & 51 & 64 & 9 \\
\hline & 2 & 613 & 28 & 60 & 33 & 9 \\
\hline & 3 & 824 & 47 & 54 & 48 & 6 \\
\hline & snack & 374 & 24 & 29 & 15 & 5 \\
\hline \multirow{4}{*}{ Week 6} & 1 & 554 & 21 & 61 & 33 & 7 \\
\hline & 2 & 357 & 15 & 29 & 26 & 4 \\
\hline & 3 & 681 & 36 & 58 & 31 & 4 \\
\hline & snack & 396 & 24 & 35 & 15 & 6 \\
\hline
\end{tabular}




\section{Participants}

Participants of the AQMP study were recruited via email and social media posts from a fitness center in Santa Clara, CA. To participate in this study, recruits had to be at least 18 years of age and be able to stand and work in a kitchen for 4 hours straight without assistance. A convenience sampling strategy was utilized for this study. Due to space limitations in the kitchen, ten was the maximum number of participants permitted. There was also a monetary commitment for study participants. The program cost the participants $\$ 100$ each per week for food, supplies, and the kitchen rental. The first ten people to respond to the recruitment email or social media post and consent to participate in the study became the study participants. The study protocol was approved (\#F18138) by the Institution Review Board, and written consent was obtained by each participant prior to commencement of the experiment.

\section{Survey}

A web-based survey (Qualtrics, Provo, UT) was administered to collect physical activity, cooking and consumption behaviors, cooking attitudes, and cooking self-efficacy data. The survey was adapted from the Cooking with a Chef program, which was validated by Michaud ${ }^{16}$ in a study with parents and caregivers of preschool children. Questions were organized into four different sections: physical activity, cooking attitudes, meal consumption behaviors, and cooking self-efficacy. The physical activity section measured the self-reported frequency and duration of weekly activity at 3 different intensity levels: walking, moderate exercise, and vigorous exercise. The cooking attitudes section measured how respondents feel about cooking (eg, like it or not, find it 
frustrating, degree of work involved). Five-point Likert responses for the cooking attitudes scale included: strongly disagree, disagree, neutral, agree, and strongly agree. Meal consumption behaviors included questions about the frequency of consumption of home-cooked breakfast, lunch and dinner per week; and cooking selfefficacy questions measured confidence in culinary skills and food preparation techniques and utilized a 5-point Likert scale that ranged from 1 (not confident at all) to 5 (extremely confident).

\section{Anthropometrics}

Several anthropometric measures were taken at T1, T2, and T3. Height was measured using a stadiometer (Seca 213, Hamburg, Germany); a digital scale was used to measure weight (Tanita BF-522W, Tokyo, Japan), and waist and hip circumference were measured with a measuring tape (Seca 201, Hamburg, Germany). In addition, an InBody ${ }^{\circledR} 570$ Multi-frequency Bioelectrical Impedance Analyzer (Biospace, Inc. Seoul, Korea) was used to measure weight, skeletal muscle mass, body fat mass, body fat percentage, and BMI. InBody has been shown to be comparable, $r=0.94(p<0.001)$ to dual-energy x-ray absorptiometry (DXA) for measuring body composition. ${ }^{17}$

\section{Dietary Recalls}

In order to analyze nutrient intake, a total of nine 24-hour dietary recalls were collected. Two weekdays and 1 weekend day were collected for each participant at each time point (T1, T2 and T3). A computer assisted dietary recall method, the Automated Self-Administered 24-hour (ASA24) Dietary Assessment Tool, version 2018, was used. ASA24 was developed by the National Cancer Institute, Bethesda, MD. ASA24 has been 
shown to be comparable, yet slightly less accurate than the traditional intervieweradministered Automated Multiple-Pass Method in adults (AMPM) (80\% vs 83\%), compared to actual intake. ${ }^{18}$

\section{Data Analysis}

The primary outcome measured in this study was frequency of consumption of homecooked meals. The secondary outcomes included cooking attitudes, cooking selfefficacy, and anthropometric measures. Survey data were coded for the cooking attitudes and cooking self-efficacy sections. The codebook and coding information can be viewed in the validation thesis by Michaud. ${ }^{16}$ Cooking attitudes were captured with 20 questions in the survey. Seven cooking self-efficacy questions captured the participants' confidence in cooking and meal preparation tasks. The combined totals for each section and time point were summed and analyzed. ASA24 data were exported to an excel file and reviewed and cleaned per ASA24 guidelines. ${ }^{19}$ Nutrient outlier cut points were based on the 5th and 95th percentile of intakes for kcal, protein, fat, and vitamin C, from NHANES data. ${ }^{19}$ Due to the small sample size, this study did not meet the sample size guidelines for parametric tests. Therefore, nonparametric statistical tests were used to analyze the data. A Friedman's 2-way ANOVA was used to establish statistical significance between any of the three time points (T1, T2, and T3). A post hoc Dunn test was used to determine which two specific time points were significantly different.

\section{RESULTS}

Demographic information was captured in the Qualtrics survey. Nine out of ten participants were female. The average age and standard deviation of the group were $46 \pm$ 
11 years. Sixty percent of participants were white, not of Hispanic origin, 30\% were Asian or Pacific Islander, and 10\% were Hispanic/Latino. The majority were employed full time (90\%), and self-reported being overweight by at least 5-10 lbs. (90\%). All participants were unmarried and at minimum had some college or technical school education.

Anthropometric data (Table 2) showed a significant decrease in several of the measurements taken. Weight decreased significantly between $\mathrm{T} 1$ and $\mathrm{T} 3$, fat mass decreased significantly between $\mathrm{T} 1$ and $\mathrm{T} 2$, and $\mathrm{T} 1$ and $\mathrm{T} 3$, and $\mathrm{BMI}$ decreased significantly between T1 and T2. There were no significant changes in skeletal muscle mass throughout the study.

Table 2. Changes in Anthropometric Data Between Pre-Program, Post-Program, and 3 Months Post-Program

\begin{tabular}{lccccccc}
\hline & \multicolumn{2}{c}{$\begin{array}{c}\text { Pre-Program } \\
\text { (T1) }\end{array}$} & \multicolumn{2}{c}{$\begin{array}{c}\text { Post-Program } \\
\text { (T2) }\end{array}$} & $\begin{array}{c}\text { 3 months Post- } \\
\text { Program (T3) }\end{array}$ & $\begin{array}{c}\text { Friedman's } \\
\text { test }\end{array}$ \\
\cline { 2 - 8 } & Mean & S.D. & Mean & S.D. & Mean & S.D. & p-value \\
\hline Weight (kg) & $85.1^{\mathrm{a}}$ & 27.8 & $83.6^{\mathrm{a}, \mathrm{b}}$ & 27.4 & $83.3^{\mathrm{b}}$ & 27.4 & 0.03 \\
Waist to hip ratio & $0.89^{\mathrm{a}}$ & 0.07 & $0.85^{\mathrm{a}}$ & 0.07 & $0.86^{\mathrm{a}}$ & 0.08 & 0.04 \\
Skeletal Muscle & $29.6^{6}$ & 5.3 & 29.8 & 5.4 & 29.3 & 5.4 & 0.41 \\
Mass (kg) & & & & & & & \\
Body Fat Mass (kg) & $32.0^{\mathrm{a}}$ & 21.6 & $30.3^{\mathrm{b}}$ & 21.4 & $28.6^{\mathrm{b}}$ & 22.4 & 0.01 \\
Body Fat \% & 34.8 & 11.0 & 33.6 & 11.9 & 33.9 & 12.0 & 0.08 \\
BMI $\left(\mathrm{kg} / \mathrm{m}^{2}\right)$ & $31.7^{\mathrm{a}}$ & 9.4 & $31.1^{\mathrm{b}}$ & 9.3 & $31.0^{\mathrm{a}, \mathrm{b}}$ & 9.4 & 0.03 \\
\hline
\end{tabular}

Note. Superscript letters indicate significant differences between groups using the post hoc

Dunn test; Statistical Significance $=\mathrm{P}<0.05$

We saw increases from $\mathrm{T} 1$ to $\mathrm{T} 3$ in both familiarity $(\mathrm{P}=0.01)$ and confidence $(\mathrm{P}=0.02)$ in regards to utilizing AQMP techniques. There were increases in overall cooking attitudes from $\mathrm{T} 1$ to $\mathrm{T} 3(\mathrm{P}=0.01)$ and overall cooking self-efficacy from $\mathrm{T} 1$ to $\mathrm{T} 2$ $(\mathrm{P}=0.008)$. Table 3 shows the totals for cooking attitudes and self-efficacy. 
Table 3. Average Total Cooking Attitudes and Self-Efficacy Scores

Pre-Program Post-Program 3 Months Post- Friedman's

(T1)

(T2)

Program (T3) Test

\begin{tabular}{lccccccc} 
& Mean & S.D. & Mean & S.D. & Mean & S.D. & P-value \\
\hline Cooking Attitudes & $77.6^{\mathrm{a}}$ & 10.2 & $76.2^{\mathrm{a}, \mathrm{b}}$ & 19.8 & $85.3^{\mathrm{b}}$ & 12.6 & 0.01 \\
Cooking Self-Efficacy & $28.0^{\mathrm{a}}$ & 3.6 & $31.8^{\mathrm{b}}$ & 3.7 & $31.3^{\mathrm{a}, \mathrm{b}}$ & 4.2 & 0.002 \\
\hline
\end{tabular}

Note. Superscript letters indicate significant differences between groups using the post hoc Dunn test; Statistical Significance $=\mathrm{P}<0.05$

Home-cooked meal consumption (Figures 1 \& 2) was captured with 6 survey questions regarding the frequency of consumption of breakfast, lunch, and dinner. Home-cooked meal percentage was calculated in order to analyze the consumption patterns of food away from home. A significant increase was seen in percent consumption of home-cooked dinners between T1 and T2 $(\mathrm{P}=0.04)$. AQMP frequency increased from $3.3 \pm 4.9$ at $\mathrm{T} 1$ to $7.1 \pm 6.0$ at $\mathrm{T} 2$, then decreased back to $5.4 \pm$ 5.9 at $\mathrm{T} 3(\mathrm{P}=0.05)$.

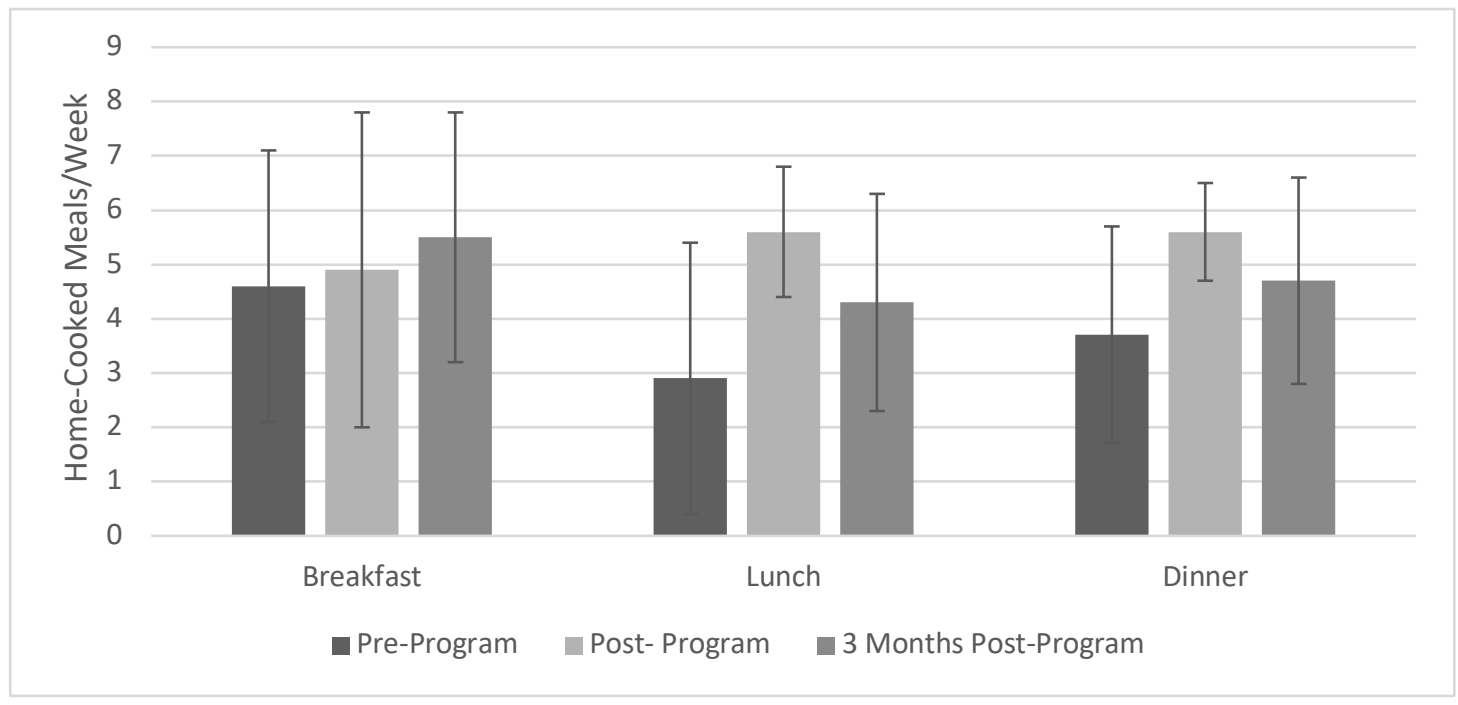

Figure 1. Average home-cooked meal consumption per week ( \pm 1 S.D.) 


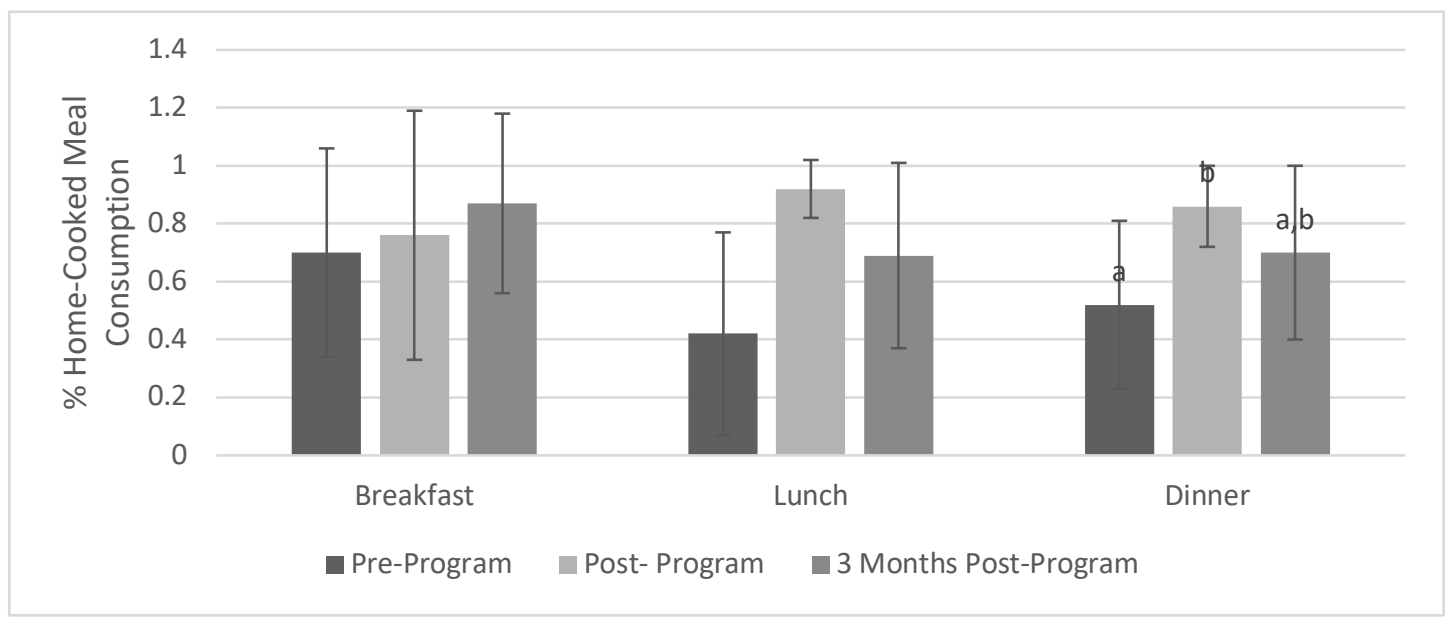

Figure 2. Percent home-cooked meal consumption ( \pm 1 S.D.) Letters indicate significant differences between groups using the post hoc Dunn test; Statistical Significance $=\mathrm{P}<0.05$

Table 4 shows the number of completed ASA24 dietary recalls per participant. Two recalls were omitted as per ASA24 reviewing and cleaning guidelines. Both dietary recalls had total kcals lower than 600 , which is the lower nutrient outlier cut point for adult women $\geq 12$ years old. Cut points are based on the 5th and 95th percentile of intake for NHANES data. ${ }^{19}$

Table 4. ASA Dietary Recall Submissions Per Participant

$\begin{array}{ccc}\begin{array}{c}\text { Pre-Program } \\ \text { (T1) }\end{array} & \text { Post-Program } & \text { 3 Months Post- } \\ \text { (T2) } & \text { Program (T3) }\end{array}$

\begin{tabular}{lccccccccc}
\hline Participant & Recall & Recall & Recall & Recall & Recall & Recall & Recall & Recall & Recall \\
ID & $\mathbf{1}$ & $\mathbf{2}$ & $\mathbf{3}$ & $\mathbf{1}$ & $\mathbf{2}$ & $\mathbf{3}$ & $\mathbf{1}$ & $\mathbf{2}$ & $\mathbf{3}$ \\
\hline AQMP01 & $\mathrm{x}$ & $\mathrm{x}$ & $\mathrm{x}$ & $\mathrm{x}$ & $\mathrm{x}$ & $\mathrm{x}$ & $\mathrm{x}$ & $\mathrm{x}$ & $\mathrm{x}$ \\
AQMP02 & $\mathrm{x}$ & $\mathrm{x}$ & $\mathrm{x}$ & $\mathrm{x}$ & $\mathrm{x}$ & $\mathrm{x}$ & $\mathrm{x}$ & $\mathrm{x}$ & $\mathrm{x}$ \\
AQMP03 & $\mathrm{x}$ & $\mathrm{x}$ & $\mathrm{x}$ & $\mathrm{x}$ & $\mathrm{x}$ & $\mathrm{x}$ & $\mathrm{x}$ & $\mathrm{x}$ & \\
AQMP04 & $\mathrm{x}$ & $\mathrm{x}$ & $\mathrm{x}$ & $\mathrm{x}$ & $\mathrm{x}$ & $\mathrm{x}$ & $\mathrm{x}$ & $\mathrm{x}$ & $\mathrm{x}$ \\
AQMP05 & $\mathrm{x}$ & $\mathrm{x}$ & $\mathrm{x}$ & $\mathrm{x}$ & $\mathrm{x}$ & $\mathrm{x}$ & $\mathrm{x}$ & $\mathrm{x}$ & $\mathrm{x}$ \\
AQMP07 & & & & $\mathrm{x}$ & $\mathrm{x}$ & $\mathrm{x}$ & $\mathrm{x}$ & $\mathrm{x}$ & $\mathrm{O}$ \\
AQMP08 & $\mathrm{x}$ & $\mathrm{x}$ & $\mathrm{x}$ & $\mathrm{x}$ & $\mathrm{x}$ & & $\mathrm{x}$ & $\mathrm{x}$ & \\
AQMP09 & $\mathrm{x}$ & $\mathrm{x}$ & $\mathrm{x}$ & $\mathrm{x}$ & $\mathrm{x}$ & $\mathrm{o}$ & $\mathrm{x}$ & $\mathrm{x}$ & $\mathrm{x}$ \\
AQMP10 & $\mathrm{x}$ & $\mathrm{x}$ & $\mathrm{x}$ & $\mathrm{x}$ & $\mathrm{x}$ & $\mathrm{x}$ & $\mathrm{x}$ & $\mathrm{x}$ & $\mathrm{x}$ \\
AQMP11 & $\mathrm{x}$ & $\mathrm{x}$ & $\mathrm{x}$ & $\mathrm{x}$ & $\mathrm{x}$ & $\mathrm{x}$ & $\mathrm{x}$ & $\mathrm{x}$ & $\mathrm{x}$ \\
\hline
\end{tabular}

Note: An $\mathrm{x}$ represents a completed dietary recall, an o represents an omitted dietary recall. 
Table 5 shows the energy intake and expenditures of the participants at T1, T2, and T3. No statistical significance was seen in any of the intake or output measurements for the study.

\begin{tabular}{|c|c|c|c|c|c|c|c|}
\hline & \multicolumn{2}{|c|}{$\begin{array}{l}\text { Pre-Program } \\
\text { (T1) }\end{array}$} & \multicolumn{2}{|c|}{$\begin{array}{c}\text { Post- } \\
\text { Program (T2) }\end{array}$} & \multicolumn{2}{|c|}{$\begin{array}{l}3 \text { Months Post- } \\
\text { Program (T3) }\end{array}$} & \multirow{2}{*}{$\begin{array}{c}\begin{array}{c}\text { Friedman's } \\
\text { Test }\end{array} \\
\text { P-value }\end{array}$} \\
\hline & Mean & S.D. & Mean & S.D. & Mean & S.D. & \\
\hline $\begin{array}{l}\text { Energy Intake } \\
\text { (kcal) }\end{array}$ & 1646.7 & 626.7 & 1574.0 & 366.6 & 1708.2 & 655.2 & 0.72 \\
\hline PRO Intake (g) & 82.6 & 17.8 & 106.6 & 28.7 & 98.5 & 39.5 & 0.12 \\
\hline FAT Intake (g) & 73.0 & 27.0 & 62.3 & 25.8 & 66.6 & 30.7 & 0.37 \\
\hline CHO Intake (g) & 163.1 & 98.8 & 147.6 & 42.7 & 159.1 & 77.1 & 0.72 \\
\hline $\begin{array}{l}\text { Low intensity } \\
\text { exercise } \\
(\mathrm{min} / \text { week) }\end{array}$ & 118.7 & 103.7 & 404.0 & 876.8 & 94.5 & 64.1 & 0.52 \\
\hline $\begin{array}{l}\text { Moderate } \\
\text { intensity exercise } \\
(\mathrm{min} / \text { week })\end{array}$ & 101.0 & 102.8 & 113.5 & 182.0 & 99.0 & 54.9 & 0.55 \\
\hline $\begin{array}{l}\text { Vigorous } \\
\text { Exercise } \\
\text { (min/week) }\end{array}$ & 221.0 & 140.5 & 247.4 & 149.1 & 253.0 & 223.0 & 0.91 \\
\hline
\end{tabular}

\section{DISCUSSION}

This pilot study evaluated the effects of the novel AQMP program on the frequency of home-cooked meal consumption, cooking attitudes, cooking self-efficacy, and changes in anthropometric measurements. The results demonstrate that the group-based 6-week AQMP program may have contributed to sustained effects on participants' cooking 
attitudes, cooking self-efficacy, home-cooked dinner consumption, weight, body fat mass, and BMI. Without a control group to compare our results to, we are unable to conclude that the AQMP program was the reason for the changes in attitudes, behaviors, and anthropometric measures. The greatest changes in attitudes related to the effort and energy required to cook, suggesting that the participants found cooking to be less work and less tiring than expected at the end of the program compared to the beginning. These are similar findings to other studies that examined cooking attitudes. ${ }^{8,10,20}$ Increases in familiarity with and confidence in utilizing AQMP techniques were also seen between baseline and the 3 month follow up. When grouped together, the sum for all 20 cooking attitudes questions significantly increased from 77.6 out of a possible 100 points, or $77.6 \%$ at baseline, to $85.3(85.3 \%)$ three months post-program. This $7.7 \%$ increase in overall cooking attitudes indicates that the participants had a more positive attitude towards cooking 3 months after completing the AQMP program, and suggests that the participants continued to utilize AQMP techniques after the program had finished.

Similar results were seen with cooking self-efficacy. Of a possible 35 points for 7 questions, the baseline total average was $28(80 \%)$. The total significantly increased to 31.8 (92\%) immediately post-program, and then dropped slightly to $89 \%$ at the 3 month follow up. These results are inconsistent with previous studies that show cooking selfefficacy continuing to increase over time. ${ }^{11,20}$ Enrollment based on randomized sampling would increase the generalizability of these findings. More research is needed to apply these findings to a broader population. 
The data for average home-cooked breakfast, lunch, and dinner consumption looks promising, as there were sustained increases from baseline to 3 months post-program for all three meals. The percentage of home-cooked meal consumption also had sustained increases from baseline to 3 months post-program for breakfast, lunch, and dinner, with a significant increase in the percentage of consumption of home-cooked dinners from preprogram to post-program $(\mathrm{p}=0.04)$. This implies that the participants ate more homecooked food and less food away from home for dinners throughout the AQMP program, compared to before the program. These results correspond with similar studies in the literature that evaluate group-based nutrition programs. ${ }^{8,20}$

Home-cooked breakfast consumption increase steadily at each time point. This was surprising, as the AQMP program did not provide breakfast for the participants. The steady increases could be attributed to increased motivation to eat more home-cooked meals as a by-product of the AQMP program, as seen in previous group-based cooking studies. ${ }^{8,10,20}$ Or it is possible that the participants were consuming their prepared AQMP meals for breakfast instead of lunch or dinner.

At baseline, the average consumption of home-cooked lunches was 2.9 per week and dinners was 3.7. After the 6-week AQMP program, the average consumption of homecooked lunches and dinners rose to 5.6 per week, respectively. During the 3 month follow up, the consumption of home-cooked lunches fell slightly to 4.3 per week and 4.7 for dinner. This pattern corresponds with the proposed hypothesis. There are several possible reasons for this. One may be the absence of the group setting after the conclusion of the program. Group settings tend to provide more motivation and 
accountability. ${ }^{11,21}$ Grocery shopping is another possible reason for the decrease in consumption of home-cooked lunches and dinners at the 3 month follow up. During the program, the program facilitator did all of the shopping for food and supplies. Once the program ended, the facilitator no longer completed this step. The time and energy required for grocery shopping could be a deterrent to consistent AQMP. ${ }^{6,13}$

Changes in anthropometrics and body composition were also analyzed. As obesity rates continue to rise, AQMP could be a possible weight management strategy by providing higher quality, portion controlled meals compared to meals away from home. Significant decreases in weight, body fat mass, and BMI were seen. This is an interesting phenomenon, because, as demonstrated in Table 5 , there were no significant changes in intake (kcal, protein, fat, and carbohydrates) or physical activity. One explanation for this could be inaccurate reporting during the dietary recalls. Despite the availability of a variety of dietary assessment techniques including 24-hour dietary recalls, food diaries, and online applications, inaccurate assessment of dietary intake is common..$^{22-24}$ Our reliance on self-reported data for the $24 \mathrm{hr}$ dietary recalls may bias our results due to underreporting, which may result from deliberate or inadvertent omission of consumed foods. ${ }^{22-24}$

In addition, the average energy intake for each time point was below the Dietary Guidelines for Americans recommendation of 1800-2200 kcals per day for adult females, and 2400-3000 kcals per day for adult males. ${ }^{25}$ It could be that there was a learning curve with the ASA24 online reporting system, as the average kcals did increase slightly by the 3 month follow up, yet at the same time, average weight decreased. It is important to 
note that our measures of diet composition, kcals, protein, fat, and carbohydrates are not conclusive indicators of overall diet quality, as vitamins, minerals and other vital nutrients such as water are not being considered. On a population level, reducing the amount of fat, sugar, carbohydrates, and energy intake are goals of the Dietary Guidelines of America, ${ }^{15}$ but for any given individual, changes in these measures may not result in improved diet quality. It is also important to note that, due to the absence of a control group, our results do not allow for causal inferences.

\section{IMPLICATIONS FOR RESEARCH AND PRACTICE}

To our knowledge, this was the first scientific experiment to examine the effects of advance quantity meal prep on human subjects. Therefore, it is impossible to compare our results with those of other studies. This study suggests that AQMP could increase the frequency of consumption of home-cooked meals, as well as provide benefits in body composition and weight management. This program could be used to help increase consumption of home-cooked meals among people with limited time to cook during the work week. With proper controls and a larger sample size, future experiments could build on this study and strengthen the evidence in favor of the health benefits of AQMP. Future research questions could relate to diet quality, time-savings, and/or financial implications of AQMP. 


\section{REFERENCES}

1. Expert PM, Jensen MD, Ryan DH, et al. Executive summary: Guidelines (2013) for the management of overweight and obesity in adults. Obesity. 2014;22:S5-S39.

2. Hales CM, Carroll MD, Fryar CD, Ogden CL. Prevalence of obesity among adults and youth: United states, 2015-2016. NCHS Data Brief No. 288. https:/www.cdc.gov/nchs/data/databriefs/db288.pdf. Published October 2017. Accessed December 12, 2018.

3. Saksena MJ, Okrent AM, Anekwe TD, et al. America's Eating Habits: Food Away From Home. Economic Information Bulletin No. 196. https://www.ers.usda.gov/webdocs/publications/90228/eib-196.pdf. Published September 2018. Accessed May 20, 2019.

4. Levy J, Auld G. Cooking classes outperform cooking demonstrations for college sophomores. J Nutr Educ Behav. 2004;36(4):197-203.

5. Mills S, Brown H, Wrieden W, White M, Adams J. Frequency of eating home cooked meals and potential benefits for diet and health: Cross-sectional analysis of a population-based cohort study. Int J of Behav Nutr Phys Act. 2017;14(1):109.

6. Tiwari A, Aggarwal A, Tang W, Drewnowski A. Cooking at home: A strategy to comply with U.S. dietary guidelines at no extra cost. Am J Prev Med. 2017;52(5):616-624.

7. Wolfson JA, Bleich SN. Is cooking at home associated with better diet quality or weight-loss intention? Public Health Nutr. 2015;18(8):1397-1406.

8. Herbert J, Flego A, Gibbs L, et al. Wider impacts of a 10-week community cooking skills program-Jamie's ministry of food, Australia. BMC Public Health. 2014;14(1):1161.

9. Jordan KC, Freeland-Graves JH, Klohe-Lehman DM, et al. A nutrition and physical activity intervention promotes weight loss and enhances diet attitudes in low-income mothers of young children. Nutr Res. 2008;28(1):13-20.

10. Warmin A, Sharp J, Condrasky MD. Cooking with a chef: A culinary nutrition program for college aged students. Top Clin Nutr. 2012;27(2):164-173.

11. Keller HH, Gibbs A, Wong S, Vanderkooy P, Hedley M. Men can cook! Development, implementation, and evaluation of a senior men's cooking group. $J$ Nutr Elder. 2004;24(1):71-87.

12. Becker MH. The health belief model and personal health behavior. Health Educ Monogr. 1974;2:324-473.

13. Macdiarmid JI, Loe J, Kyle J, McNeill G. "It was an education in portion size". Experience of eating a healthy diet and barriers to long term dietary change. Appetite. 2013;71:411-419.

14. Pelletier JE, Laska MN. Balancing healthy meals and busy lives: Associations between work, school, and family responsibilities and perceived time constraints among young adults. J Nutr Educ Behav. 2012;44(6):481-489.

15. US Department of Agriculture and US Department of Health and Human Services. Dietary Guidelines for Americans, 2010. https://health.gov/dietaryguidelines/2010/ Published 2011. Accessed July 7, 2019. 
16. Michaud P. Development and evaluation of instruments to measure the effectiveness of a culinary and nutrition education program. (Thesis, Clemson University). 2007.

17. Miller RM, Chambers TL, Burns SP, Godard MP. Validating InBody® 570 multifrequency bioelectrical impedance analyzer versus DXA for body fat percentage analysis. Med Sci Sports Exerc. 2016;48(5 Suppl 1):991.

18. Kirkpatrick SI, Subar AF, Douglass D, et al. Performance of the automated selfadministered 24-hour recall relative to a measure of true intakes and to an interviewer-administered 24-h recall. Am J Clin Nutr. 2014;100(1):233-240.

19. Automated Self-Administered 24-hour (ASA24) Dietary Assessment Tool, version (2018), developed by the National Cancer Institute, Bethesda, MD. https://epi.grants.cancer.gov/asa24. Accessed January 2019.

20. Flego A, Herbert J, Waters E, et al. Jamie's ministry of food: Quasi-experimental evaluation of immediate and sustained impacts of a cooking skills program in Australia. PLoS One. 2014;9(12):e114673.

21. Wing RR, Jeffery RW. Benefits of recruiting participants with friends and increasing social support for weight loss and maintenance. J Consult Clin Psychol. 1999;67(1):132.

22. Klesges RC, Eck LH, Ray JW. Who underreports dietary intake in a dietary recall? evidence from the second national health and nutrition examination survey. $J$ Consult Clin Psychol. 1995;63(3):438.

23. Kristal AR, Andrilla CHA, Koepsell DT, Diehr PH, Cheadle A. Dietary assessment instruments are susceptible to intervention-associated response set bias. J Am Diet Assoc. 1998;98(1):40-43.

24. Macdiarmid J, Blundell J. Assessing dietary intake: Who, what and why of underreporting. Nutr Res Rev. 1998;11(2):231-253.

25. DeSalvo KB, Olson R, Casavale KO. Dietary guidelines for Americans. JAMA. 2016;315(5):457-458. 


\section{Chapter 3}

\section{Summary and Recommendations}

\section{Summary}

For the past few decades, a vast body of evidence has accumulated that shows that consuming home-cooked meals more often leads to a healthier overall diet and better health outcomes (Guthrie et al., 2002; Mancino et al., 2010; Mills, Brown, Wrieden, White, \& Adams, 2017; Nielsen \& Popkin, 2003; Saksena et al., 2018; Tiwari, Aggarwal, Tang, \& Drewnowski, 2017; Wolfson \& Bleich, 2014). There are fewer studies, however, that aim to create strategies for people to prepare and consume home-cooked meal more often. In fact, studies show that the predominance of home cooking has significantly decreased in the last 50 years (Saksena et al., 2018; Smith, Ng, \& Popkin, 2013), and with it, diet quality has declined and obesity rates have steadily increased. This pilot study was created to present and evaluate a potential method for increasing the consumption of home-cooked meals. Advance quantity meal prep (AQMP), is a term invented and defined by the research team to describe the process of planning and preparing healthy meals in bulk, ahead of time, to eat at a later date. This strategy can be attractive to time-starved people who want to consume more homecooked meals. By preparing and packaging several meals at once, people with little time during the work week now have healthy, home-cooked meals available when needed.

This study was the first to examine the effects of AQMP on home-cooked meal consumption, cooking attitudes, cooking self-efficacy, and changes in anthropometric measurements. This experiment has demonstrated that the 6-week AQMP program may 
have contributed to sustained increases in participants' cooking attitudes, cooking selfefficacy and home-cooked dinner consumption, and significant and sustained decreases in weight, body fat mass, and BMI. Proper controls are needed to show that the AQMP program was the reason for the changes in attitudes, behaviors, and anthropometric measures. AQMP could be a viable strategy for health conscious people to increase consumption of home-cooked meals.

\section{Recommendations}

As there are no historical data on this subject, this pilot study sought to examine the potential benefits of AQMP from a behavioral standpoint. This study aimed to increase the frequency of consumption of home-cooked meals by creating and implementing a group program designed to facilitate behavior change. The present study's research questions were limited to home-cooked meal consumption and anthropometric measures. With proper controls, this research could be verified and strengthened with larger and more diverse samples and different research questions.

As the present study's population was $90 \%$ female with a history of regular physical activity, this strategy could be beneficial for males, people of lower socio-economic status, adolescents and young adults, and non-exercisers. A formal education component could be added to this program to teach proper cooking techniques, basic knife skills, and food safety. Additional research questions could evaluate AQMP on diet quality, time saved on meal preparation each week, decisional fatigue in regards to food choices, and the cost effectiveness of AQMP. 


\section{References}

Abood, A. D., Black, D. R., \& Feral, D. (2003). Nutrition education worksite intervention for university staff: Application of the health belief model. Journal of Nutrition Education and Behavior, 35(5), 260-267. doi:10.1016/S1499-4046(06)60057-2

Becker, M.H. (1974). The health belief model and personal health behavior. Ann Arbor, MI: Health Education Monographs.

Bhutani, S., Schoeller, D.A., Walsh, M. C., \& McWilliams, C. (2018). Frequency of eating out at both fast-food and sit-down restaurants was associated with high body mass index in non-large metropolitan communities in Midwest. American Journal of Health Promotion, 32(1), 75-83. doi:10.1177/0890117116660772

Clark, N. M., \& Dodge, J. A. (1999). Exploring self-efficacy as a predictor of disease management. Health Education \& Behavior, 26(1), 72-89. doi:10.1177/109019819902600107

Costa, A. I. d. A. (2013). Conceptualization and measurement of personal norms regarding meal preparation. International Journal of Consumer Studies, 37(6), 596-604. doi:10.1111/ijcs. 12036

Ducrot, P., Méjean, C., Aroumougame, V., Ibanez, G., Allès, B., Kesse-Guyot, E., Hercberg, S., ... Péneau, S. (2017). Meal planning is associated with food variety, diet quality and body weight status in a large sample of French adults. The International Journal of Behavioral Nutrition and Physical Activity, 14(1), 12. doi:10.1186/s12966-017-0461-7

Duffey, K. J., Gordon-Larsen, P., Steffen, L. M., Jacobs Jr, D. R., \& Popkin, B. M. (2009). Regular consumption from fast food establishments relative to other restaurants is differentially associated with metabolic outcomes in young adults. The Journal of Nutrition, 139(11), 2113-2118. doi:10.3945/jn.109.109520

Expert, P. M., Jensen, M. D., Ryan, D. H., Donato, K. A., Apovian, C. M., Ard, J. D., . . . Yanovski, S. Z. (2014). Executive summary: Guidelines (2013) for the management of overweight and obesity in adults. Obesity, 22, S5-S39. doi:10.1002/oby.20821

Flego, A., Herbert, J., Waters, E., Gibbs, L., Swinburn, B., Reynolds, J., \& Moodie, M. (2014). Jamie's ministry of food: Quasi-experimental evaluation of immediate and sustained impacts of a cooking skills program in Australia. PloS One, 9(12), e114673. doi:10.1371/journal.pone.0114673 
Fulkerson, J. A., Kubik, M. Y., Rydell, S., Boutelle, K. N., Garwick, A., Story, M., ... Dudovitz, B. (2011). Focus groups with working parents of school-aged children: what's needed to improve family meals?. Journal of Nutrition Education and Behavior, 43(3), 189-193. doi:10.1016/j.jneb.2010.03.006

Gillis, L. J., \& Bar-Or, O. (2003). Food away from home, sugar-sweetened drink consumption and juvenile obesity. Journal of the American College of Nutrition, 22(6), 539-545. doi:10.1080/07315724.2003.10719333

Guenther, P. M., Casavale, K. O., Reedy, J., Kirkpatrick, S., Hiza, H., Kuczynski, K., ... Krebs-Smith, S. M. (2013). Update of the healthy eating index: HEI-2010. Journal of the Academy of Nutrition and Dietetics, 113(4), 569-580. doi:10.1016/j.jand.2012.12.016

Guthrie, J.F., Lin, B., \& Frazao, E. (2002). Role of food prepared away from home in the American diet, 1977-78 versus 1994-96: Changes and consequences. Journal of Nutrition Education and Behavior, 34(3), 140-50. doi:10.1016/S1499-4046(06)60083-3

Hales, C. M., Carroll, M. D., Fryar, C. D., \& Ogden, C. L. (2017). Prevalence of obesity among adults and youth: United States, 2015-2016 (NCHS Data Brief No. 288). Retrieved from https://www.cdc.gov/nchs/products/databriefs/db288.htm

Harnack, L. J., Jeffery, R.W., Boutelle, K.N. (2000). Temporal trends in energy intake in the United States: An ecologic perspective. The American Journal of Clinical Nutrition, 71(6), 1478-1484. doi:10.1093/ajen/71.6.1478

Harris, J. M., \& Shiptsova, R. (2007). Consumer demand for convenience foods: demographics and expenditures. Journal of Food Distribution Research, 38(8562016-57845), 22-36.

Herbert, J., Flego, A., Gibbs, L., Waters, E., Swinburn, B., Reynolds, J., \& Moodie, M. (2014). Wider impacts of a 10-week community cooking skills program-Jamie's ministry of food, Australia. BMC Public Health, 14(1), 1161.

Jackson, E. S., Tucker, C. M., \& Herman, K. C. (2007). Health value, perceived social support, and health self-efficacy as factors in a health-promoting lifestyle. Journal of American College Health, 56(1), 69-74. doi:10.3200/JACH.56.1.69-74

Jordan, K. C., Freeland-Graves, J. H., Klohe-Lehman, D. M., Cai, G., Voruganti, V. S., Proffitt, J. M. ...Bohman, T. M. (2008). A nutrition and physical activity intervention promotes weight loss and enhances diet attitudes in low-income mothers of young children. Nutrition Research, 28(1), 13-20.

doi:10.1016/j.nutres.2007.11.005 
Keller, H. H., Amie Gibbs, A., Wong, S., Vanderkooy, P. \& Hedley, M. (2004) Men can cook! Development, implementation, and evaluation of a senior men's cooking group. Journal of Nutrition for the Elderly, 24(1), 71-87.

doi:10.1300/J052v24n01_06

Lachat, C., Nago, E., Verstraeten, R., Roberfroid, D., Van Camp, J., \& Kolsteren, P. (2012). Eating out of home and its association with dietary intake: A systematic review of the evidence. Obesity Reviews, 13(4), 329-346. doi:10.1111/j.1467789X.2011.00953.x

Lang, T., \& Caraher, M. (2001). Is there a culinary skills transition? Data and debate from the UK about changes in cooking culture. Journal of the HEIA, 8(2), 2-14.

Levy, J., \& Auld, G. (2004). Cooking classes outperform cooking demonstrations for college sophomores. Journal of Nutrition Education and Behavior, 36(4), 197203. doi:10.1016/S1499-4046(06)60234-0

Mancino, L., Todd, J.E., Guthrie, J.F., \& Lin, B.H. (2010). How food away from home affects children's diet quality (ERR-104). Retrieved from https://www.ers.usda.gov/publications/pub-details/?pubid=44756

Macdiarmid, J. I., Loe, J., Kyle, J., \& McNeill, G. (2013). "It was an education in portion size". Experience of eating a healthy diet and barriers to long-term dietary change. Appetite, 71, 411-419. doi:10.1016/j.appet.2013.09.012

U.S. Department of Agriculture and U.S. Department of Health and Human Services. (2011). Dietary guidelines for Americans, 2010. Retrieved from https://health.gov/dietaryguidelines/2010/

Michaund, P. (2007). Development and evaluation of instruments to measure the effectiveness of a culinary and nutrition education program. (Thesis, Clemson University).

Mills, S., Brown, H., Wrieden, W., White, M., \& Adams, J. (2017). Frequency of eating home cooked meals and potential benefits for diet and health: Cross-sectional analysis of a population-based cohort study. International Journal of Behavioral Nutrition \& Physical Activity, 14(1), 109.

National Restaurant Association (2019). 2019 Restaurant Industry Fact book. Retrieved from http://restaurant.org/research/reports/state-of-restaurant-industry

Nielsen, S.J., \& Popkin, B.M. (2003). Patterns and trends in food portion sizes, 1977-1998. Journal of the American Medical Association, 289(4), 450453. doi:10.1001/jama.289.4.450 
Pelletier, J. E., \& Laska, M. N. (2012). Balancing healthy meals and busy lives: Associations between work, school, and family responsibilities and perceived time constraints among young adults. Journal of Nutrition Education and Behavior, 44(6), 481-489. doi:10.1016/j.jneb.2012.04.001

Saksena, M. J., Okrent, A. M., Anekwe, T. D., Cho, C., Dicken, C., Effland, A., ... \& Jo, Y. (2018). America's Eating Habits: Food Away From Home (No. 281119). Retrieved from https://www.ers.usda.gov/webdocs/publications/90228/eib196.pdf

Smith, L. P., Ng, S. W., \& Popkin, B. M. (2013). Trends in US home food preparation and consumption: Analysis of national nutrition surveys and time use studies from 1965-1966 to 2007-2008. Nutrition Journal, 12(1), 45. doi:10.1186/1475-2891$12-45$

Stankevitz, K., Dement, J., Schoenfisch, A., Joyner, J., Clancy, S. M., Stroo, M., \& Østbye, T. (2017). Perceived barriers to healthy eating and physical activity among participants in a workplace obesity intervention. Journal of Occupational and Environmental Medicine, 59(8), 746-751. doi:10.1097/JOM.0000000000001092

Todd, J. E., Mancino, L., \& Lin, B. H. (2010). The Impact of Food Away From Home on Adult Diet Quality (ERR-90). Retrieved from https://www.ers.usda.gov/webdocs/publications/46352/8170_err90_1_.pdf

Tiwari, A., Aggarwal, A., Tang, W., \& Drewnowski, A. (2017). Cooking at home: A strategy to comply with U.S. dietary guidelines at no extra cost. American Journal of Preventive Medicine, 52(5), 616-624. doi:10.1016/j.amepre.2017.01.017

Warmin, A., Sharp, J., \& Condrasky, M. D. (2012). Cooking with a chef: A culinary nutrition program for college-aged students. Topics in Clinical Nutrition, 27(2), 164-173. doi:10.1097/TIN.0b013e3182542417

Wolfson, J. A., \& Bleich, S. N. (2014). Is cooking at home associated with better diet quality or weight-loss intention? Public Health Nutrition, 18(8), 1397-1406. doi:10.1017/S1368980014001943

Wolfson, J. A., Frattaroli, S., Bleich, S. N., Smith, K. C., \& Teret, S. P. (2017). Perspectives on learning to cook and public support for cooking education policies in the United States: A mixed methods study. Appetite, 108, 226-237. doi:10.1016/j.appet.2016.10.00 


\section{APPENDIX A}

\section{IRB Approval letter}

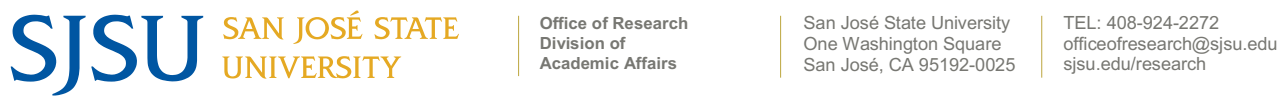

SAN JOSE STATE UNIVERSITY

HUMAN SUBJECTS INSTITUTIONAL REVIEW BOARD

IRB Notice of Approval

Date of Approval: 12/21/2018

Study Title: The Effects of a 6-Week Group Advance Quantity Meal Prep Program on the Frequency of Consumption of Home Cooked Meals

Primary Investigator(s): Dr. John Gieng, Dr. Jamie Kubota, Dr. Adrianne Widaman

Student(s): Shannon Mendez

Other Team Members:

Funding Source: None

IRB Protocol Tracking Number: F18138

Type of Review

$\square$ Exempt Registration: Category of approval $\$ 46.104(\mathrm{~d})()$

$\bigotimes \quad$ Expedited Review: Category of approval $\$ 46.110(a)(2,4,7)$

$\square$ Full Review

$\square$ Modifications

$\square$ Continuing Review

Special Conditions

$\square$ Waiver of signed consent approved

$\square$ Waiver of some or all elements of informed consent approved

$\square$ Risk determination for device:

$\square$ Other:

Continuing Review

$\bigotimes$ Is not required. Principal Investigator must file a status report with the Office of Research one year from the approval date on this notice to communicate whether the research activity is ongoing. Failure to file a status report will result in closure of the protocol and destruction of the protocol file after three years. 


\section{APPENDIX B}

\section{CONSENT FORM FOR YOUR PARTICIPATION IN A RESEARCH STUDY}

\section{TITLE OF THE STUDY}

The effects of a 6-week group advance quantity meal prep program on the frequency of consumption of home-cooked meals

\section{RESEARCHER TEAM}

Dr. John Gieng, PhD, Assistant Professor, San José State University, Department of Nutrition, Food Science, \& Packaging

Shannon Mendez, Graduate Student, San José State University, Department of Nutrition, Food Science, \& Packaging

\section{INTRODUCTION}

This consent may contain information that you do not understand. Please ask the investigator or the study staff to explain words or information that you do not clearly understand.

This is a research study. Research studies include only people who choose to participate. As a study participant you have the right to know about the procedures that will be used in this research study so that you can make the decision whether or not to participate. The information presented here is simply an effort to make you better informed so that you may give or withhold your consent to participate in this research study.

This study is being sponsored by the Department of Nutrition, Food Science, and Packaging, San José State University.

In order to participate in this study, it will be necessary to give your written consent.

\section{WHY IS THIS STUDY BEING CONDUCTED?}

In America today, time starved people are cooking less frequently and eating more and more meals away from home. This has contributed greatly to the obesity epidemic. Many studies show that as frequency of consumption of home-cooked meals increases, so does diet quality.

The overall purpose of this study is to examine if a 6-week group-based advance quantity meal prep program has a long term effect on the frequency of consumption of homecooked meals. A secondary aim for this study is to obtain and examine anthropometric and biochemical measurements before, after, and three months after the conclusion of the 
program, to determine if the program has an effect on body composition and/or biochemical markers. Anthropometric measurements include height, weight, waist circumference, body fat percentage, and lean muscle mass. We will use a fingerstick blood collection procedure to measure levels of HbAlc (diabetes marker), CRP (inflammation marker), and homocysteine (cardiovascular disease marker).

\section{WHAT IS INVOLVED IN THE STUDY?}

Pre-program Survey and Measurements: All study participants will meet at FNS Training Center the day before the first meal prep meeting. The purpose of this meeting is to complete the initial study survey, take anthropometric measurement and complete biochemical measurements.

You will be expected to complete the following steps:

1. Read and sign the consent form (approx. 10 mins)

2. Complete biochemical measurements for c-reactive protein, hemoglobin A1c, and homocysteine. (approx. 5 mins)

a. About $80 \mu \mathrm{L}$ ( $\sim 2-3$ drops) of blood will be collected by a standard finger stick procedure using a sterile lancet needle for this assay.

3. Complete anthropometric measurements: Height, InBody body composition scan (weight, body fat percentage, BMI, and lean muscle mass), waist to hip ratio, and blood pressure. (approx. 10 mins)

4. Written survey regarding cooking behaviors, demographics and physical activity (approx. 20 mins)

Meal Prep Program: 10 study participants will meet at the Santa Clara American Legion Post 419 for six consecutive Sundays from $8 \mathrm{am}-12 \mathrm{pm}$ to prepare and package ten meals and five snack packs per participant. This program will be led by the program facilitator who will provide guidance, education and recipes to the participants. The program facilitator will be responsible for purchasing the food items and ingredients for the weekly menus prior to the Sunday group meetings. The menus will change weekly and the participants will be assigned different tasks each week during the program in order to learn new skills and techniques. The ten meals are designed to satisfy the dietary requirements for lunch and dinner for five days. The snack packs will include mostly fruits and vegetables, and can be eaten all at once or throughout the day.

Post Program Measurements: Within 1 week after the conclusion of the 6-week program, all study participants will meet at FNS Training Center to complete postprogram anthropometric and biochemical measurements.

1. Complete biochemical measurements for c-reactive protein, hemoglobin A1c, and homocysteine. (approx. 5 mins)

2. Complete anthropometric measurements: Height, InBody body composition scan (weight, body fat percentage, BMI, and lean muscle mass), waist to hip ratio, and blood pressure. (approx. 10 mins) 
3 Month Follow up Survey and Measurements: 3 months after the conclusion of the program, all study participants will meet at FNS Training Center to complete the follow up survey and final anthropometric and biochemical measurements.

1. Complete biochemical measurements for c-reactive protein, hemoglobin Alc, and homocysteine. (approx. 5 mins)

2. Complete anthropometric measurements: Height, InBody body composition scan (weight, body fat percentage, BMI, and lean muscle mass), waist to hip ratio, and blood pressure. (approx. 10 mins)

3. Written survey regarding cooking behaviors (approx. 20 mins)

\section{HOW LONG WILL I BE IN THE STUDY?}

Completion of all data collection will take approximately 4.5 months, however, the meal prep program will only last 6 weeks.

\section{WHAT ARE THE RISKS OF THE STUDY?}

Potential risks of this study are the same risks you would encounter when preparing and cooking meals at home. These risks include, but are not limited to, cutting yourself with a knife while chopping food items, burning yourself on hot pots or pans, slipping and falling on wet floors, and illness from foodborne pathogens.

Fingerstick procedure: Drawing blood from a finger stick may, in rare cases- cause discomfort, bruising, prolonged bleeding and infection at the site of puncture. To minimize risk, we will swab the site of puncture with alcohol to disinfect the area, use disposable lancet and capillary tubes to collect blood and apply pressure to the puncture site following the blood draw to minimize bruising. We will cover the puncture with an appropriate dressing and provide subjects with information on how to monitor for signs of infection. The blood collected will be used to measure various health biomarkers. This biochemical analysis will occur within 3 days of the blood collection, after which, your sample will be securely discarded.

No information that could result in your identification will be released or reported.

\section{POTENTIAL BENEFITS}

This experiment is designed to develop skills, confidence and habits that enable you to batch meal prep healthy meals on an ongoing basis once the program has finished. There are also social benefits to this program, as it is a group program, you will have the opportunity to meet new people. Additionally, your anthropometric and biochemical measurement results will be made available to you upon request after your completion of or exit from of the study.

\section{COMPENSATION}


There is no compensation for participation in this study.

\section{WHAT ARE THE COSTS?}

The total cost for the program is $\$ 600$. Two payments of $\$ 300$ are due on the first and fourth Sunday meetings of the program. Payment will be accepted via check and made out to San Jose State University. This fee covers the cost of reusable meal prep containers that the participants will use each week to package their meals and keep once the program has concluded, food and ingredients for each weeks meals and snacks, and rental of the kitchen. To participate in this study, subjects must commit to attending every measurement meeting and meal prep meeting. If you are unable to attend any of the meal prep meeting once the program has started, no refunds will be given.

\section{CONFIDENTIALITY}

Information will be stored in the investigator's locked file and identified by code only. Original data collection instruments, along with a code key connecting your name to specific information about you, will be locked in a separate, secure location, and only accessible by research team members affiliated with this research study, unless you give written permission to share your information.

Data and findings will be presented to the Nutrition, Food Science and Packaging Department and potentially among larger conferences and publications, however, any personal information that could identify you will be removed or changed before files are shared with other researchers or results are made public.

\section{PARTICIPANT RIGHTS}

Your participation in this study is completely voluntary. You can refuse to participate in the entire study or any part of the study without any negative effect on your participation in the 6-week meal prep program. You also have the right to skip any question you do not wish to answer. This consent form is not a contract. It is a written explanation of what will happen during the study if you decide to participate. You will not waive any rights if you choose not to participate, and there is no penalty for stopping your participation in the study.

\section{QUESTIONS OR PROBLEMS}

You are encouraged to ask questions at any time during this study.

- For further information about the study, please contact John Gieng, PhD at john.gieng@sjsu.edu or 408-924-1277.

- Complaints about the research may be presented to Dr. Ashwini Wagle, Chair of the Department of Nutrition Food Science and Packaging at ashwini.wagle@sjsu.edu or 408-924-3110.

- For questions about participants' rights or if you feel you have been harmed in any way by your participation in this study, please contact Dr. Pamela Stacks, 
Associate Vice President of the Office of Research, San Jose State University, at 408-924-2479.

\section{SIGNATURES}

Your signature indicates that you voluntarily agree to be a part of the study, that the details of the study have been explained to you, that you have been given time to read this document, and that your questions have been answered. You will receive a copy of this consent form for your records.

\section{Participant Signature}

$\overline{\text { Participant's Name (printed) } \quad \text { Participant's Signature Date }}$

\section{Researcher Statement}

I certify that the participant has been given adequate time to learn about the study and ask questions. It is my opinion that the participant understands his/her rights and the purpose, risks, benefits, and procedures of the research and has voluntarily agreed to participate.

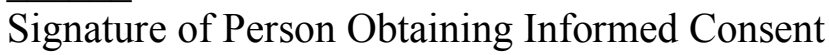

Date 


\section{APPENDIX C}

Survey instrument

\section{AQMP Survey}

\section{Start of Block: Demographics}

Q29 Demographics

Q1 What is your current age?

Q2 What is your gender?
Male (1)
Female (2)

Q3 How do you describe yourself?

Black, not of Hispanic origin (1)

White, not of Hispanic origin (2)

Hispanic/Latino (3)

Asian or Pacific Islander (4)

American Indian/Alaskan Native (5)

Mixed/Other (6) 
Q4 What is the highest level of education you completed?

Some high school (1)

High school graduate or GED (2)

Some college or technical school (3)

College graduate (4)

Master's degree or higher (5)

Q6 What is your present work/employment status?
Employed full time (1)
Employed part time (2)
Unemployed (3)
Retired (4)
Student (5)
Homemaker (6) 
Q7 What is your present marital status?

Single, never been married (1)

Married (2)

Divorced, separated, or widowed (3)

Single, living with a partner (4)

Q8 How many children under the age of 18 live in your home?
0 (1)
$1-2(2)$
3-4 (3)
5 or more (4)

Q9 How would you describe your current weight status?

Underweight (1)

Normal weight (2)

Overweight by $5-10$ pounds (3)

Overweight by $11-20$ pounds (4)

Overweight by more than 20 pounds (5) 


\section{Q28 Physical Activity}

Q22 In the past week, how many times have you WALKED for recreation or exercise and/or to get to and from places for at least 10 minutes continuously?

$\nabla 0(2) \ldots 30(32)$

Q23 Please estimate the total time (minutes) you spent walking in the past week.

Q26 In the past week, how many times did you do MODERATE exercise or other physical activity (around the house or at work) which DID NOT make you breathe harder or puff and pant? (e.g., digging in the garden, moderate cycling, raking leaves, dancing).

$\nabla 0(1) \ldots 30(31)$

Q27 Please estimate the total time (minutes) you spent doing moderate exercise or physical activity in the past week.

Q24 In the past week, how many times did you do VIGOROUS exercise or other physical activity (around the house or at work) which made you breathe harder or puff and pant? (e.g., Jogging or running, heavy gardening, netball, chopping wood, vigorous swimming, heavy laboring).

$\nabla 0(1) \ldots 30(31)$ 
Q25 Please estimate the total time (minutes) you spent doing vigorous exercise or physical activity in the past week.

Page Break

Q10 For each item below, indicate the extent to which you agree or disagree with the statement about cooking. 


\begin{tabular}{|c|c|c|c|}
\hline $\begin{array}{c}\text { Strongly } \\
\text { Disagree (1) }\end{array}$ & Disagree (2) & $\begin{array}{c}\text { Neither } \\
\text { agree nor } \\
\text { disagree (3) }\end{array}$ & Agree (4) \\
\hline
\end{tabular}

\section{I do NOT like to cook because it takes too much time. (1) \\ Preparing meals at home would NOT improve the health of my diet. (2) \\ Cooking meals is a good use of my time. (3) \\ I enjoy cooking. (4) \\ It is important to know how to prepare food. (5) \\ Cooking is fun. (6) \\ I do NOT like to prepare meals at home because it costs too much money. (7) \\ It is NOT important that I know how to cook. (8) \\ Cooking is interesting. (9)}


Meals made at home are

affordable.

It is important to eat the recommended 2 cups of fruit each day. (11)

It is important to eat the recommended $2 \frac{1}{2}$ cups of vegetables each day. (12)

It is easy to prepare meals.

Cooking is frustrating.

I like trying new recipes.

It is too much work to cook.

Making meals at home helps me to eat more healthfully.

I find cooking tiring. (18)

I am familiar with advance quantity meal prep techniques.

(19) 
I am confident

utilizing

advance

quantity meal

prep

techniques.

(20)

\section{Page Break}

Q20 Definition of home-made: Foods prepared by yourself or by someone in your household from scratch or with minimally processed ingredients.

Q12 In the past 30 days, how many times per week on average did you consume breakfast?

$\boldsymbol{\nabla} 0(1) \ldots 7$ (8)

Q13 In the past 30 days, how many times per week on average did you consume a homemade breakfast?

$\nabla 0(1) \ldots 7(8)$

Q14 In the past 30 days, how many times per week on average did you consume lunch?

$\nabla 0(1) \ldots 7$ (8) 
Q15 In the past 30 days, how many times per week on average did you consume a homemade lunch?

$\nabla 0(1) \ldots 7(8)$

Q16 In the past 30 days, how many times per week on average did you consume dinner?

$\boldsymbol{\nabla} 0(1) \ldots 7$ (8)

Q17 In the past 30 days, how many times per week on average did you consume a homemade dinner?

$\boldsymbol{\nabla} 0$ (1) ... 7 (8)

Q18 Definition of advance quantity meal prep (batch meal prep): The intentional process of planning and preparing healthy meals ahead of time to eat at a later date. In the past 30 days, how many times have you batch meal prepped?

$\boldsymbol{\nabla} 0$ (1) ... 20 (21)

Page Break

Q21 For each item below, indicate the extent to which you feel confident about performing the particular activity. Select ONE box for EACH question. 


\begin{tabular}{|c|c|c|c|c|c|}
\hline & $\begin{array}{l}\text { NOT at all } \\
\text { confident (1) }\end{array}$ & $\begin{array}{c}\text { NOT very } \\
\text { confident (2) }\end{array}$ & $\begin{array}{c}\text { Neither } \\
\text { confident not } \\
\text { unconfident } \\
\text { (3) }\end{array}$ & Confident (4) & $\begin{array}{c}\text { Extremely } \\
\text { confident (5) }\end{array}$ \\
\hline $\begin{array}{l}\text { Cook from } \\
\text { basic } \\
\text { ingredients } \\
\text { (ex: whole } \\
\text { lettuce heads, } \\
\text { fresh } \\
\text { tomatoes, raw } \\
\text { chicken). (1) }\end{array}$ & & & & & \\
\hline $\begin{array}{c}\text { Follow a } \\
\text { written recipe } \\
\text { (ex: preparing } \\
\text { fresh salsa } \\
\text { from } \\
\text { tomatoes, } \\
\text { onion, garlic, } \\
\text { jalapeno } \\
\text { peppers). (2) }\end{array}$ & & & & & \\
\hline $\begin{array}{c}\text { Prepare } \\
\text { dinner from } \\
\text { items you } \\
\text { currently } \\
\text { have in your } \\
\text { pantry and } \\
\text { refrigerator. } \\
\text { (3) }\end{array}$ & & & & & \\
\hline $\begin{array}{l}\text { Use knife } \\
\text { skills in the } \\
\text { kitchen. (4) }\end{array}$ & & & & & \\
\hline $\begin{array}{l}\text { Plan } \\
\text { nutritious } \\
\text { meals. (5) }\end{array}$ & & & & & \\
\hline $\begin{array}{c}\text { Use basic } \\
\text { cooking } \\
\text { techniques. } \\
(6)\end{array}$ & & & & & \\
\hline $\begin{array}{c}\text { Reusing } \\
\text { leftovers for } \\
\text { another meal. } \\
\text { (7) }\end{array}$ & & & & & \\
\hline
\end{tabular}




\section{APPENDIX D}

Email:

\section{Email and Social Media Recruitment Script and Flyer}

Hello FNS member,

This is Coach Shannon from FNS Training Center. As you may know, I am currently in the Master's Program for Nutrition at San Jose State University. I am starting my graduate research project soon and need people to participate in a study I am conducting. I have designed a 6-Week Group Meal Prep Program and need 20 participants who can start mid-January. There will be two different groups (10 people in each group). One group (group A) will participate in the full program, which includes meeting at the Santa Clara Veterans Center on Sunday mornings for 6 weeks starting on January 13, 2019, from $8 \mathrm{am}-12 \mathrm{pm}$, to prepare and package 10 meals and 5 snack packs per person per week (all your lunches and dinners for the work week made in one shot!). The second group (group B) will receive the recipes, grocery shopping lists, and workflow for the 6 week program, but will not participate in the group cooking sessions. The intention for this group is that you will complete the meal prep on your own, at home, each week.

Because the full program group will be leaving with 10 meals and 5 snack packs each week, there is a cost associated with group A. The total cost for this program is $\$ 600$, which can be broken into 2 payments of $\$ 300$. This fee is to cover the cost of the food, reusable meal prep containers that you will keep at the end of the program, and rental of the kitchen. There is no cost associated with group B.

This is a research study, so you will be asked to complete a written survey, an InBody scan, and biochemical measurements (a drop of blood from a finger prick) before the program, at the end of the program, and again 3 months after the completion of the program. To participate in group A, you must be able to attend the entire program (all 6 meal prep meetings and measurement meetings). To participate in group B, you must be able to attend all measurement meetings.

Please note, the meals will include animal proteins and potential allergens, so if you do not eat meat, are a picky eater, or have food allergies, this program will not be a good fit for you.

If you are interested in participating, please let me know asap, and will send you all of the specific dates and details. I am also happy to answer any questions that you may have.

Thank you-

Shannon Mendez 


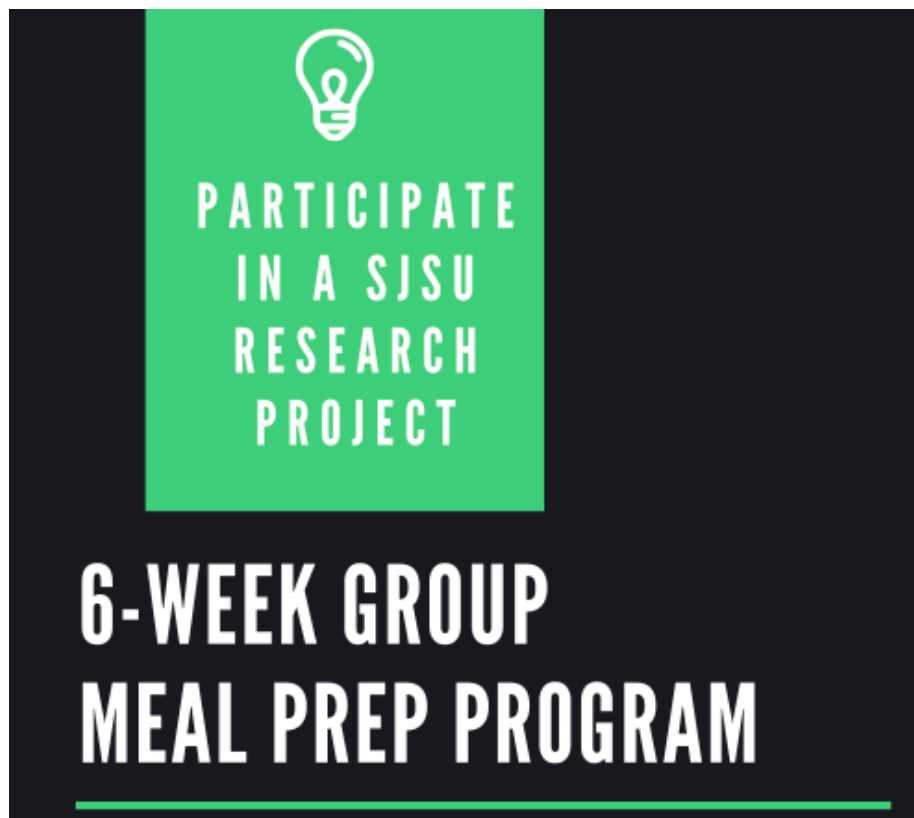

\section{Group A}

- Meet once per week on Sundays from 8am-12pm$-1 / 13,1 / 20,1 / 27,2 / 3$, 2/10, 2/17, 2019

- Prepare and package 10 meals and $\mathbf{5}$ snack packs/participant/week

- 10 participants maximum

- $\$ 100 /$ person per week-Must commit to all 6 weeks

Studies show that eating home cooked meals more frequently is associated with lower BMI and body fat percentage and an overall healthier diet. This study seeks to provide a solution that enables people to regularly eat healthy home cooked meals and save time overall on meal related tasks.

Interested in participating?

Email Shannon Mendez at Shannon.Mendez@sjsu.edu
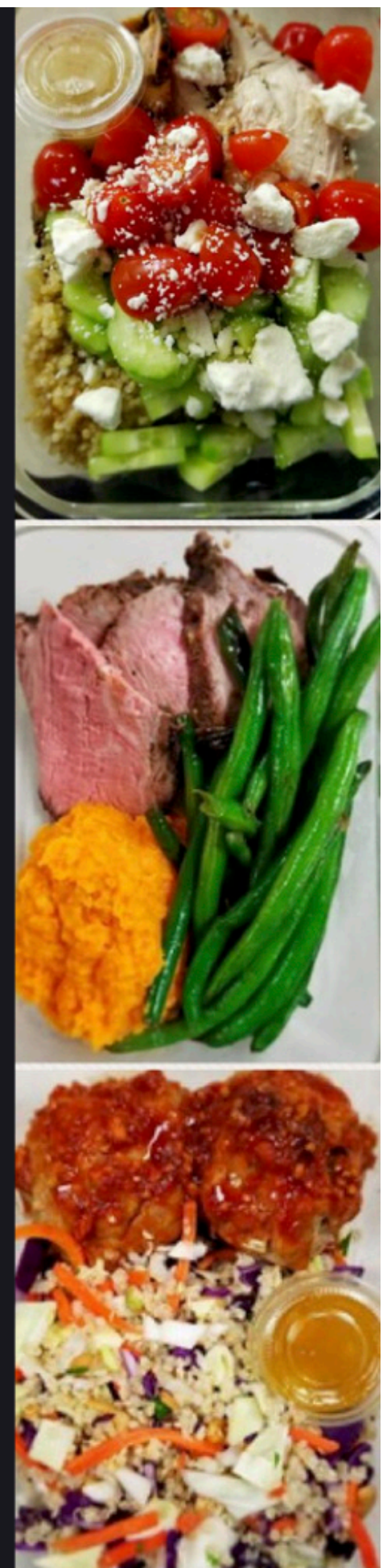


\section{APPENDIX E}

\section{Week 1 Recipes:}

\section{Pineapple Chicken Meal Prep Bowls:}

Prep time: 5 mins Cook time : 25 mins Total time: $\mathbf{3 0}$ mins Serves: 4 Ingredients:

- 1.5 lbs chicken breast, cut into 1" pieces

- Pineapple juice, reserved from pineapple chunks

- 4 tbsp low sodium soy sauce, divided

- $1 / 2$ tsp ground ginger

- 2 tbsp coconut oil, divided

- $1 / 2$ tsp garlic

- $1 / 2$ tsp red pepper flakes

- 1 green pepper, diced

- 20 oz can pineapple chunks

- juice of 1 lime

- 8 cups spinach

\section{Instructions:}

1. In a gallon bag, add chicken, reserved pineapple juice, 2 tbsp of soy sauce, and ginger. Mix together and set aside for at least $\mathbf{3 0}$ mins.

2. In a skillet, melt 1 tbsp of coconut oil. Add garlic and red pepper flakes, cook for 1-2 mins. Add in green pepper. Cook until tender, about 7-8 minutes. Add pineapple chunks, cook an additional 2-3 mins and remove from skillet.

3. Add in remaining tbsp of coconut oil, add chicken and cook until no longer pink 8-10 mins. Add remaining 2 tbsp of soy sauce and lime juice. Mix and add pineapple and green pepper mixture back in. Let simmer 2-3 minutes.

4. Divide into 4 meal prep containers and add 1/2 cup of Coconut Lime Quinoa. When you heat it up in the microwave, add 2 cups of raw spinach. The cooking process will wilt the spinach. Mix all together and enjoy!

\section{Coconut Lime Quinoa:}

Prep time: 1 mins Cook time : 12 mins Total time: 13 mins Serves: 4 Ingredients:

3 cups coconut milk (any variety)

1.5 cups quinoa

2 limes, juice + zest

\section{Instructions:}

1. Add coconut milk, quinoa and lime juice to small sauce pan. Bring to a boil, cover and reduce to simmer for 12-15 minutes until all the liquid has been absorbed.

2. Remove from the heat stir and let stand until cool.

3. Add 1/2 cup cooked quinoa to each Pineapple Chicken meal prep bowl 


\section{Ground Turkey Burrito Bowls:}

Prep time: 10 mins Cook time : 15 mins Total time: 25 mins Serves: 4 Ingredients:

- 1 cup dry brown rice

- 2 tbsp olive oil

- 2 lbs ground turkey

- 2 tbsp taco seasoning

- $1 / 2$ cup salsa verde

- 15 oz can black beans, drained and rinsed

- 15 oz can whole kernel corn, drained

- 1 package grape tomatoes

- Fresh cilantro and lime wedges for garnish

\section{Instructions:}

1. Cook rice according to package directions and set aside.

2. Heat olive oil in a heavy skillet over med high heat.

3. Add ground turkey and use a wooden spoon to crumble it, breaking it up.

4. After it is broken up a bit and starting to brown, add the taco seasoning.

5. Stir well.

6. Add salsa verde and stir to combine.

7. Brown the turkey completely, crumbling as you go.

8. Once browned, remove from heat and drain off the grease.

9. Slice tomatoes in half

10. Divide the rice, black beans, ground turkey, corn and tomatoes into 4 meal prep containers. 


\section{One Pan Italian Sausage and Veggies:}

Prep time: 15 mins Cook time : 30 mins Total time: 45 mins Serves: 4 Ingredients:

- 1 cup dry brown rice

- 2 large carrots

- 2 red potatoes

- 1 medium zucchini

- 2 red peppers

- 1 head broccoli

- 16 oz Smoked Italian Turkey or Chicken Sausage

Seasonings:

- $1 / 2$ tbsp EACH: dried basil, dried oregano, dried parsley, garlic powder

- $1 / 2$ tsp EACH: onion powder, dried thyme

- $1 / 3$ cup freshly grated Parmesan cheese

- $41 / 2$ tbsp olive oil Instructions:

1. Cook rice according to package directions and set aside.

2. Preheat the oven to 400 degrees F. Line a large sheet pan with parchment paper or foil (easy clean-up) and set aside.

3. Prep the veggies: *It is important to prep the veggies according to directions to ensure they all cook at the same time*

4. Peel and very thinly slice the carrots. Wash and (if desired peel) chop the red potatoes. You want the pieces quite small here. (I halve the potatoes and then cut each half into 10-12 pieces)

5. Halve the zucchini and then cut *thick* coins of zucchini. Coarsely chop the broccoli. Remove the stems and seeds from the peppers and chop into medium-sized pieces. Chop the sausage into thick coins.

6. Pour all the veggies and sausage on the sheet pan.

7. In a small bowl combine all of the seasonings and salt and pepper if desired (I use about 1/8 teaspoon pepper and $1 / 2$ teaspoon salt) with the olive oil. Stir to combine.

8. Pour the seasoning \& oil mixture on top of the veggies and sausage and thoroughly toss to coat.

9. Place in the heated oven for 15 minutes. Remove and toss around the veggies + sausage and return to the oven for another 10-20 minutes or until veggies are crisp tender.

10. Remove and divide into 4 meal prep containers. Add 1/2 cup of brown rice to each. 


\section{Week 2 Recipes:}

\section{Honey Sriracha Turkey Meatballs:}

Prep time: 15 mins Cook time : 20 mins Total time: 35 mins Serves: 4

\section{Ingredients:}

- For the meatballs:

- $1 \mathrm{lb}$. lean ground turkey

- $1 / 2$ cup whole wheat panko

- breadcrumbs

- 1 eggs

- 1/4 cup green onions, chopped

- $1 / 4$ tsp. garlic powder

- $1 / 4$ tsp. salt

- $1 / 4$ tsp. black pepper
- For the sauce:

- 1/8 cup Sriracha

- 1.5 Tbsp reduced sodium soy sauce

- 1.5 Tbsp rice vinegar

- 1.5 Tbsp honey

- $1 / 2$ Tbsp grated fresh ginger

- 1.5 cloves garlic, minced

- $1 / 2$ tsp. toasted sesame oil

\section{Instructions:}

1. Preheat oven to 375 degrees $F$.

2. In a large bowl, mix together turkey, breadcrumbs, eggs, green onions, garlic powder and salt/pepper until well combined. Shape mixture into $1 \frac{1 / 2}{2}$ in balls (about 20 balls) and place spaced apart on prepared baking sheets lightly sprayed with cooking spray.

3. Bake meatballs for 20 to 25 minutes, or until browned and cooked through.

4. While the meatballs are baking, combine all the ingredients for the sauce in a small saucepan and bring to a boil over medium heat, whisking continuously. Reduce heat and simmer for 8 to 10 minutes (the sauce will start to thicken) then toss with the meatballs.

5. Separate into 4 meal prep containers with Asian quinoa slaw salad. 


\section{Asian Quinoa Slaw Salad:}

Prep time: 20 mins Cook time : 0 mins Total time: 20 mins Serves: 4 Ingredients:

- For the salad:

- 3 cups Red or Green Cabbage (1/2 lb shredded)

- 1/2 cup cooked Quinoa

- 1/2 cup Carrots

- 1/8 cup fresh Cilantro (chopped)

- 1/3 cup Cashews (chopped, toasted)

- 1 Tbsp Black Sesame Seeds (toasted)

- 1 Green Onions (sliced, keep green and white separated)
- For the Sesame Ginger Vinaigrette (yields $3 / 4$ cup):

- 1/4 cup Rice Vinegar

- 1 tsp fresh Ginger (finely grated)

- 1 clove Garlic (finely grated)

- 1 Tbsp Honey

- pinch of Salt and Pepper

- 1/4 cup Olive Oil

- 2 Tbsp Sesame Oil (golden or dark is fine)

\section{Instructions:}

For the salad:

1. In a large mixing bowl, combine cabbage, cooked quinoa, carrots, cilantro, cashews, sesame seeds, and green onions (whites); cover and refrigerate until ready to dress with vinaigrette.

For the Sesame Ginger Vinaigrette:

2. In a mixing bowl or glass, whisk together rice vinegar, ginger, garlic, honey, salt, and pepper.

3. Slowly drizzle in the olive oil and sesame oil, continually whisking until well-blended and creamy.

4. Cover and refrigerate until ready to use; garnish with green onion (green part). 


\section{Chili Lime Steak Bites:}

Prep time: 10 mins Cook time : 5 mins Total time: 15 mins Serves: 4 Ingredients:

- 1 lbs Top Sirloin Steak

- $1 / 2$ tsp salt

- $1 / 2$ tsp black pepper

- $1 / 2$ tsp garlic powder

- 2 tbsp chili paste

- 1 tbsp honey

- 2 tbsp olive oil

- 2 limes, zested and juiced

\section{Instructions:}

1. Cut the steak into 1-inch strips, then cut the strips into 1/2-inch pieces.

2. Place the steak in a small bowl, and sprinkle with salt, pepper and garlic powder. Stir to coat the steak in the spices.

3. Add the chili paste and the honey, and stir again to coat the steak completely.

4. Place a 10-inch cast iron skillet over med-high heat. Add the olive oil and swirl around the pan. Add the steak to the pan in a single layer. If it doesn't sizzle and hiss, the pan is not hot enough.

5. Sear the steak for 1 minute before touching it, then flip the steak bites with tongs or a spatula. Sear the steak on the second side for an additional 1 minute, then remove the steak from the pan. Once cooled a little bit, separate into 4 meal prep containers.

6. Add the lime zest and juice to the hot pan, stir to combine, and pour the chili lime sauce over the steak bites. 


\section{Roasted Red Potatoes:}

Prep time: 5 mins Cook time : 30 mins Total time: 35 mins Serves: 4 Ingredients:

- $1.5 \mathrm{lbs}$ baby red potatoes, quartered

- 2 tbsp olive oil

- 2 tbsp coarsely chopped fresh rosemary

- Coarse salt and freshly ground pepper Instructions:

1. Preheat oven to 425 degrees $F$.

2. Toss potatoes, oil and rosemary on a rimmed baking sheet.

3. Spread out potatoes in a single layer; season with salt and pepper.

4. Roast, stirring once halfway through cooking, until potatoes are golden brown and crisp outside and tender inside, about 30 minutes.

\section{Chili and Lime Oven Roasted Broceoli:}

Prep time: 5 mins Cook time : 15 mins Total time: 20 mins Serves: 4 Ingredients:

- 2 bundles of broccoli, trimmed and cut into equal size pieces

- 2 tbsp olive oil

- Sea salt and chili flakes to taste

- Half a lime

\section{Instructions:}

1. Preheat oven to 400 degrees $F$.

2. Lay your broccoli on a piece of foil on a baking sheet.

3. Drizzle with olive oil.

4. Sprinkle with sea salt and red chili flakes.

5. Bake for $12-15$ minutes until the floret tips are lightly browned and the stalks are tender

6. Turn the oven to broil mode and finish for one more minute to crisp the broccoli.

7. Remove the broccoli from the oven and squeeze lime juice all over. Separate into 4 meal prep containers. 


\section{Balsamic Rosemary Chicken:}

Prep time: 55 mins Cook time : 35 mins Total time: 1.5 hours Serves: 4 Ingredients:

- $1 / 2$ cup balsamic vinegar

- 2 tsp olive oil

- $11 / 2$ tbsp fresh rosemary, chopped

- 1 tbsp garlic, minced

- $1 / 2$ tsp salt

- Fresh black pepper, to taste

- Cooking spray

- 4 (5-8 oz) boneless, skinless chicken breasts

- 2 tbsp balsamic vinegar

Instructions:

1. To make marinade: in a small pot, add vinegar, oil, rosemary, garlic, salt and pepper and mix until combined. Bring up to a boil, turn heat down to medium and simmer until reduced in half, about 3 minutes. Place in refrigerator to cool for about 15 mins. For a quicker chill, place in freezer for about 5 mins.

2. Coat a $9 \times 9$ inch pan with cooking spray. Place chicken in baking dish and pour cooled marinade over chicken. Refrigerate for 30 minutes. Can be refrigerated overnight.

3. Preheat oven to 400 degrees F. Take dish out of refrigerator, cover with foil. Bake for about 35 mins until chicken is cooked thoroughly.

\section{Quinoa, Cucumber, Tomato and Feta Salad:}

Ingredients:

- 1 cup of uncooked quinoa

- 2 cucumbers, peeled and chopped into half moon pieces

- 2 cups cherry tomatoes, chopped in half

- 4 tbsp Feta cheese

- Briannas Salad Dressing, Real French Vinaigrette

Instructions:

Cook quinoa according to package instructions and divide into 4 meal prep containers. Add half of a chopped cucumber, $1 / 2$ cup of halved cherry tomatoes, and 1 tbsp of feta cheese to each meal prep bowl. When ready to eat, add 2 tbsp of Briannas french vinaigrette. 


\section{Week 3 Recipes:}

\section{Teriyaki Chicken and Vegetables:}

Prep time: 10 mins Cook time : 15 mins Total time: 25 mins Serves: 4 Ingredients:

- 3 cups uncooked brown rice

- 2 lbs chicken breast, chopped

- 12-16 oz fresh broccoli

- 2 garlic cloves, you can also use ginger

- 4-5 large carrots, sliced

- 1 red bell pepper, cut into 1" pieces

- Pepper flakes, optional

- 2 tbsp olive oil

- Teriyaki sauce:

- 2 tbsp ginger, chopped

- 1/3 cup low sodium soy sauce

- 1/3 cup cold water

- 3-4 tsp cornstarch

- 2 tbsp olive oil

\section{Instructions:}

1. Cook brown rice according to package instructions.

2. In a small bowl mix the Teriyaki sauce ingredients.

3. In a skillet, over medium to high heat, add the olive oil. Add the chicken and carrots and cook stirring occasionally until almost tender, about 6-8 minutes. Add the garlic and cook further for another minute.

4. While the chicken is cooking, place the broccoli on a microwave safe dish and microwave for 6-7 minutes. Depending on how powerful your microwave is, you may need less time.

5. Add the Teriyaki sauce from the bowl and the bell peppers to the chicken and carrots and stir for about 1-2 mins or until thickens. Turn heat off and add the broccoli and pepper flakes if using. Stir to combine.

5. Separate rice and chicken and vegetable mixture into 4 meal prep containers. 


\section{Oven Roasted Tri Tip:}

Prep time: 10 mins Cook time : 45 mins Total time: 55 mins Serves: 4 Ingredients:

- 1 tbsp olive oil

- 2 tsp paprika

- $1 / 2$ tsp salt

- $1 / 2$ tsp garlic powder

- $1 / 2$ tsp onion powder

- $1 / 2$ tsp chili powder

- 1/4 tsp cayenne pepper

- 1.5 lbs Tri Tip

\section{Instructions:}

1. Preheat oven to 350 degrees $F$.

2. Combine olive oil and spices, and let roast sit at room temp. while oven heats.

3. Line baking sheet with aluminum foil. Rub all sides of roast with spice rub mixture, and bake in preheated oven for 40-60 minutes to desired level of doneness.

4. Allow steak to rest for at least five minutes before cutting into $1 / 2$ " thick slices to serve.

\section{Roasted Squash and Zucchini:}

Ingredients:

- 2 zucchini, sliced

- 2 yellow squash, sliced

- Olive oil

- salt, pepper, garlic powder to taste

\section{Instructions:}

1. Preheat oven to $450 \mathrm{~F}$. Place chopped vegetables in bowl with olive oil and seasonings. Mix well.

2. Place all on baking sheet in a single layer and bake in lower rack in oven for 15 mins or until golden brown. 


\section{Mashed Sweet Potatoes:}

Prep time: 10 mins Cook time : 15 mins Total time: 25 mins Serves: 4 Ingredients:

- $1 \mathrm{lbs}$ sweet potatoes, peeled and cut into 2 " pieces

- 1 tbsp salted butter or coconut oil

- $1 / 4$ cup whole milk

- $1 / 4$ tsp salt

- $1 / 4$ tsp ground cinnamon

- $1 / 4$ tsp ground ginger

- pinch nutmeg

\section{Instructions:}

1. Put the sweet potatoes in a large pot and add just enough cold water to cover them. Bring to a boil and cook until fork-tender, about 15 mins. Drain and return to the potatoes to the pot on the stove top with the burner turned off. The residual heat from the pot will help any excess water burn off.

2. Add the remaining ingredients, using only $1 / 4$ cup liquid to start and adding more if needed, and mash until smooth and well-combined. 


\section{Shrimp Taco Bowl:}

Prep time: 10 mins Cook time : 15 mins Total time: 25 mins Serves: 4

\section{Ingredients:}

- Spicy Shrimp:

- 20-30 medium shrimp peeled and deveined

- 1 tablespoon olive oil

- 1 clove garlic minced

- $1 / 2$ teaspoon ground cumin

- 1/2 teaspoon chili powder

- $1 / 4$ teaspoon onion powder optional

- $1 / 4$ teaspoon kosher salt
- For the assembly:

- 2 cups cooked brown rice

- 1 cup black beans drained and rinsed

- 1 cup corn drained and rinsed

- 1 cup tomatoes diced

- $1 / 2$ cup cheddar cheese

- 2 tablespoon cilantro minced

\section{Instructions:}

1. To cook the shrimp: In a medium bowl whisk together olive oil, garlic, cumin, chili and onion powders, and salt. Add in shrimp and toss to coat completely. Cover and refrigerate for at least 10 minutes or up to 24 hours. Heat a large heavy-duty or cast iron skillet on high heat for 2 minutes. Add the olive oil and shrimp. Cook shrimp in a skillet on medium-high heat until pink and cooked through, about 5 minutes.

2. To assemble: Divide brown rice into 4 meal prep containers (1/2 cup each). Top with 5 shrimps, a scoop of black beans, corn, tomatoes, a sprinkle of cheese, cilantro and a slice of lime. Cover and refrigerate for a max of 5 days.

3. To serve: Heat bowls in the microwave for 2 minutes or until heated throughly. 


\section{Week 4 Recipes:}

\section{Honey-Balsamic Pork Tenderloin:}

Prep time: 5 mins Cook time : 25 mins Total time: 30 mins Serves: 4 Ingredients:

- 1 tsp sea salt or to taste

- $1 / 2$ tsp black pepper freshly ground

- 1 tsp Italian Seasoning

- 1 tsp garlic powder

- 1 tsp ground coriander

- 2 Tbsp olive oil (extra light) or vegetable oil

- 1 1/2 lb Pork Tenderloin

\section{Instructions:}

1. How to make Roasted Pork Tenderloin: Preheat oven to $400^{\circ} \mathrm{F}$ with the rack in the middle.

2. Trim tenderloin of fat and any silver skin and pat dry with a paper towel. Pierce pork loin all over with a fork and rub with 1 Tbsp oil.

3. Combine your seasonings and sprinkle onto the tenderloin then use your hands to rub the spices into the tenderloin until evenly coated.

4. Heat 1 Tbsp oil over med-high heat in a large oven-safe pan (cast iron or a dutch oven will work). Once oil is hot, add pork and brown on all sides (6 minutes total).

5. Place in the oven and bake uncovered at $400^{\circ} \mathrm{F}$ for $13-15 \mathrm{~min}$, flipping the tenderloin over halfway through baking. Bake until center of pork registers at least $150^{\circ} \mathrm{F}$ then transfer to a cutting board and let meat rest 5-10 min. Slice into rings and serve.

\section{Honey-Balsamic BBQ Sauce:}

\section{Ingredients:}

- 1 cup balsamic vinegar

- 3/4 cup ketchup

- $1 / 3$ cup brown sugar

- $1 / 4$ cup honey
- 1 Tbsp Worcestershire sauce

- 1 Tbsp Dijon mustard

- $1 / 4$ tsp garlic powder

- salt and pepper

Combine ingredients for Honey-Balsamic BBQ Sauce in a saucepan then stir to combine. Bring to a boil over med-high heat, stirring occasionally, then reduce heat and simmer for 45 mins or until sauce is thick. 


\section{Honey Roasted Sweet Potatoes:}

Prep time: 5 mins Cook time : 30 mins Total time: 35 mins Serves: 4-6

\section{Ingredients:}

- 2 pounds sweet potatoes 3 medium or 2 large, peeled and cut into 1-inch cubes

- 2 tablespoons olive oil

- 2 tablespoons honey

- $1 / 4$ teaspoon cinnamon

- $1 / 4$ teaspoon coarse Kosher salt

- $1 / 8$ teaspoon black pepper

Instructions:

1. Preheat oven to 425 degrees F. Line a baking sheet with parchment paper.

2. Place the sweet potatoes on the baking sheet, using two baking sheets if needed to fit all of the sweet potatoes.

3. In a small bowl, whisk together the olive oil, honey, cinnamon, salt and pepper. Pour over the sweet potatoes and toss to coat.

4. Bake for 15 minutes, stir. Continue baking for 10-15 minutes more, until sweet potatoes are tender when pierced with a fork. They should start to turn golden and caramelize around the edges.

\section{Roasted Brussels Sprouts:}

Prep time: 5 mins Cook time : 25 mins Total time: 30 mins Serves: 4 Ingredients:

- 1-1.5 lbs Brussels sprouts

- 2 tablespoons olive oil

- 1 teaspoon kosher salt

\section{Instructions:}

1. Heat oven to $400 \mathrm{~F}$

2. Trim and halve the Brussels sprouts.

3. Toss with olive oil and season with salt.

4. Transfer the seasoned sprouts to a rimmed baking sheet and arrange them cut-side down. Roast until the leaves are dark brown and crisp, and the bottoms of the sprouts are browned, 20 to 25 minutes. 


\section{Pesto Chicken \& Veggies :}

Prep time: 5 mins Cook time : 20 mins Total time: 45 mins Serves: 4

\section{Ingredients:}

- 1 cup uncooked quinoa

- 2 tablespoons olive oil

- 4 boneless, skinless chicken thighs, sliced

- salt, to taste

- pepper, to taste

- $1 \mathrm{lb}$ green beans

- 2 cups cherry tomato, halved

- $1 / 2$ cup basil pesto

\section{Instructions:}

1. Cook quinoa according to package instructions.

2. In a large pan, heat olive oil and add chicken thighs.3.. Season with salt and pepper. When the chicken is completely cooked through, remove from pan.

3. Slice into strips, and set aside.

4. Add green beans and cook until crisp tender.

5. Return the chicken strips to the pan, then add tomatoes and pesto. Stir until fully incorporated.

6. Divide pesto chicken and veggies and quinoa into 4 food storage containers and store in the refrigerator. 


\section{Steak Fajitas:}

Prep time: 10 mins Cook time : 15 mins Total time: 25 mins Serves: 4

\section{Ingredients:}

- 1 cup uncooked brown rice (cook according to package directions)

- 2 pounds skirt, flank, sirloin, or hanger steak, sliced into $1 / 2$ inch strips

- 1 red pepper, deseeded and sliced into thin strips

- 1 green or yellow pepper, deseeded and sliced into thin strips

- 1 medium onion peeled and sliced into thin strips

- 3 tablespoons olive oil

- 1 tablespoon lime juice

- $1 / 2$ teaspoon chili powder

- 1 teaspoon ground cumin

- pinch cayenne pepper

- $1 / 2$ teaspoon Kosher salt

- $1 / 2$ teaspoon fresh ground black pepper

- 2 cloves garlic minced

- 8 tortillas

\section{Instructions:}

1. Place the steak into a sealable bag. Place the peppers and onion into a separate sealable bag. Add the olive oil, lime juice, chili powder, ground cumin, cayenne pepper, salt, black pepper, and garlic to a jar with a screw top or tight fitting lid. Shake until well combined. Pour $1 / 3$ of the marinade over steak, $1 / 3$ of marinade over vegetables and reserve the remaining marinade in the jar for using when cooking the steak fajitas. Seal the bags tightly and refrigerate for one hour to overnight.

2. When ready to cook, heat a large skillet over medium-high heat. Pour the vegetables into the skillet and cook until just tender crisp, about 5 minutes.

Remove the vegetables from the skillet to a plate and add steak strips to the same skillet. When the steak is cooked throughout (about 7-10 minutes), add vegetables back to the skillet along with the reserved marinade.

3. Separate into 4 meal prep containers with brown rice. Serve with warm tortillas. 


\section{Week 5 Recipes:}

\section{Greek Chicken:}

Prep time: 20 mins Cook time : 10 mins Total time: 30 mins Serves: 4

\section{Ingredients:}

- 2 pounds boneless, skinless chicken breasts

- $1 / 4$ cup olive oil

- 3 Tbs garlic, minced (Note, adjust to preference)

- $1 / 3$ cup fresh lemon juice

- 1 Tbs red wine vinegar

- 1 Tbs dried oregano

- 1/3 cup plain Greek yogurt

- Kosher salt and freshly ground black pepper, to taste

- 1 cup quinoa

\section{Instructions:}

1. In a large plastic zip bag, combine olive oil, garlic, lemon juice, red wine vinegar, oregano, greek yogurts and salt and pepper. Massage to mix.

2. Add chicken into the bag.

3. Massage to make sure chicken is full covered and marinate for at least 20 minutes, up to 12 hours.

4. Meanwhile, make quinoa according to package instructions.

5. Drain the chicken from the marinade, discarding the marinade.

6. In a skillet, heat some olive oil over medium-high heat.

7. Add chicken when it is hot, and cook, flipping part way through. Cook approximately 3-4 minutes per side. Cooking time depends on thickness and size of the chicken. Cook until internal temp is 165 degrees.

8. Remove from pan, and let cool. 


\section{Cucumber Salad:}

\section{Ingredients:}

- 2 English cucumbers, peeled and sliced

- 2 Tbs olive oil

- 1 1/2 lbs cherry tomatoes, halved

- 1 Tbs red wine vinegar

- 1/2 cup red onions, sliced

- $1 / 2$ Tbs minced garlic

- $1 / 3$ cup lemon juice

- $1 / 2$ tsp dried oregano

\section{Instructions:}

1. Cut cucumbers into half moon pieces

2. Toss in a bowl with the lemon juice, olive oil, red wine vinegar, garlic, and oregano

3. Add cherry tomatoes and onions

\section{Tzatziki Sauce:}

\section{Ingredients:}

- 1 cup plain Greek yogurt

- 1 English cucumber, finely diced

- 1 tsp - up to 1 Tbs minced garlic (adjust to garlic preference)
- $1 / 2$ Tbs dill weed, or 1 Tbs fresh dill, chopped fine

- $11 / 2$ tsp fresh lemon juice

- 1 tsp lemon zest

- Salt and pepper to taste

\section{Instructions:}

1. Combine the Greek yogurt, cucumber, garlic, dill weed, lemon juice, lemon zest in a small bowl

2. Season with salt and pepper.

3. Refrigerate while assembling your bowls. 


\section{Pork Egg Roll in a Bowl:}

Prep time: 5 mins Cook time : 25 mins Total time: 30 mins Serves: 4 Ingredients:

- 1 cup dry brown rice

- 2 tbsp sesame oil

- 3 cloves garlic, minced

- 1/2 cup onion, diced

- 5 green onions, sliced on a bias (white and green parts)

- $1 \mathrm{lb}$ ground pork

- $1 / 2$ tsp ground ginger

- sea salt and black pepper, to taste

- 1 tbsp Sriracha or garlic chili sauce, more to taste

- 14 oz bag coleslaw

- 3 tbsp low sodium soy sauce

- 1 tbsp Rice Wine Vinegar

- 2 tbsp toasted sesame seeds

- 1 lbs sugar snap peas

\section{Instructions:}

1. Cook brown rice according to package directions.

2. Heat sesame oil in a large skillet over medium high heat.

3. Add the garlic, onion, and white portion of the green onions. Sauté until the onions are translucent and the garlic is fragrant.

4. Add the ground pork, ground ginger, sea salt, black pepper and Sriracha. Sauté until the pork is cooked through.

5. Add the coleslaw mix, low sodium soy sauce, and rice wine vinegar. Sauté until the coleslaw is tender.

6. Top with green onions and sesame seeds before serving.

7. Distribute pork mixture into 4 meal prep containers, add $1 / 2$ cup brown rice and 1 cup raw sugar snap peas (about 14). 


\section{Turkey Sausage Meatballs:}

Prep time: 10 mins Cook time : 20 mins Total time: 30 mins Serves: 4

\section{Ingredients:}

- 1 lbs ground turkey

- 2 links Jennie-O Lean Sweet Italian Turkey Sausage (remove from casing)

- 2 links Jennie-O Lean Hot Italian Turkey Sausage (remove from casing)

- 2 cups Italian breadcrumbs

- 2 eggs

- 1/4 cup green onions, diced

- $1 / 2$ tsp garlic powder

- $1 / 2$ tsp salt

- $1 / 2$ tsp black pepper
- For green salad:

- 1-2 cups mixed greens

- 1 large carrot, sliced

- 1 large cucumber, peeled and sliced

- 1 bell pepper, chopped

- 1 cup cherry tomatoes

- 8 tbsp Brianna's French Vinaigrette (divided into 4 servings)

\section{Instructions:}

1. Preheat oven to 375 degrees $F$.

2. In a large bowl, mix together turkey, sausage, breadcrumbs, eggs, green onions, garlic powder and salt/pepper until well combined. Shape mixture into $1 \frac{1}{2}$ in balls (about 20 balls) and place spaced apart on prepared baking sheets lightly sprayed with cooking spray.

3. Bake meatballs for 20 to 25 minutes, or until browned and cooked through.

4. Place 4-5 meatballs into 4 meal prep containers. Add 1-2 cups of mixed greens, carrots, cucumbers, bell peppers and tomatoes into each container. Dress with Brianna's French Vinaigrette when ready to eat. 


\section{Week 6 Recipes:}

\section{Ground Turkey Lettuce Wraps:}

Prep time: 10 mins Cook time : 15 mins Total time: 25 mins Serves: 4 Ingredients:

- 1.5 cups dry quinoa

- 1 tsp olive oil

- 1 lbs ground turkey

- 2 cloves garlic, minced

- 1 small white onion, diced

- 1/4 cup hoisin sauce

- 2 Tbsp soy sauce

- 1 Tbsp rice wine vinegar

- 1 Tbsp freshly grated ginger

- 1 tsp Sriracha

- 1 (8 ounce) can sliced water chestnuts, drained

- 2 green onions, thinly sliced

- Salt and pepper, to taste

- 1 head butter or Romain lettuce

\section{Instructions:}

1. Cook quinoa according to package instructions.

2. Add olive oil and ground turkey to a large non-stick skillet. Cook and crumble over medhigh heat until browned. Drain any fat.

3. Stir in garlic, onion, hoisin sauce, soy sauce, rice wine vinegar, ginger and Sriracha until onions have become translucent, about 1-2 minutes. Stir in chestnuts and green onions until tender, about 1-2 minutes; season with salt and pepper, to taste.

4. Separate turkey mixture and brown rice into 4 meal prep containers. When ready to eat, spoon several tablespoons of the chicken mixture into the center of the lettuce leaf and enjoy! 


\section{Maple Dijon Pork Chops with Brussels Sprouts \& Sweet Potatoes:}

Prep time: 15 mins Cook time : 30 mins Total time: 45 mins Serves: 4

\section{Ingredients:}

- 2 tablespoons olive oil

- 4 1-inch pork loin chops, bone-in

- 3 cups Brussels sprouts, washed and cut in half

- 2 sweet potatoes, peeled, washed and cut into cubes

- 1 teaspoon garlic powder

- 2 teaspoons sea salt

- 1 teaspoon ground black pepper

- 1 tablespoon Dijon mustard

- 3 tablespoons maple syrup (all natural)

- Dried rosemary

\section{Instructions:}

1. Preheat oven to 425 degrees

2. Line a baking sheet with heavy-duty aluminum foil, and add olive oil

3. Add vegetables and meat, and toss lightly in olive oil until coated

4. Season with sea salt, pepper and garlic powder

5. Spread Dijon mustard evenly on pork chops, then pour maple syrup over chops and veggies

6. Sprinkle dried rosemary over chops

7. Bake for 30 minutes, stirring vegetables occasionally, or until pork chops reach internal temperature of 160 degrees 


\section{Korean Beef Bowls:}

Prep time: 20 mins Cook time : 20 mins Total time: 40 mins Serves: 4

\section{Ingredients:}

- For the Korean Beef:

- 1/4 cup brown sugar, packed

- $1 / 4$ cup reduced sodium soy sauce

- 1 tablespoon freshly grated ginger

- 2 teaspoons sesame oil

- $1 / 2$ teaspoon Sriracha, or more to taste

- 1 tablespoon olive oil

- 2 cloves garlic, minced

- 1 pound ground beef

- 2 green onions, thinly sliced

- $1 / 4$ teaspoon sesame seeds
- 1 cup brown rice

- 4 large eggs

- 2 tablespoons olive oil

- 2 cloves garlic, minced

- 4 cups chopped spinach

\section{Instructions:}

1. Cook brown rice according to package instructions.

2. Place eggs in a large saucepan and cover with cold water by 1 inch. Bring to a boil and cook for 1 minute. Cover eggs with a tight-fitting lid and remove from heat; set aside for 8-10 minutes. Drain well and let cool before peeling and slicing in half.

3. Heat olive oil in a large skillet over medium high heat. Add garlic and cook, stirring frequently, until fragrant, about 1-2 minutes. Stir in spinach until wilted, about 2-3 minutes; set aside.

4. In a small bowl, whisk together brown sugar, soy sauce, ginger, sesame oil and Sriracha.

5. Heat olive oil in a large skillet over medium high heat. Add garlic and cook, stirring constantly, until fragrant, about 1 minute. Add ground beef and cook until browned, about 3-5 minutes, making sure to crumble the beef as it cooks; drain excess fat.

6. Stir in soy sauce mixture and green onions until well combined, allowing to simmer until heated through, about 2 minutes.

7. Place rice, eggs, spinach and ground beef mixture into meal prep containers, garnished with green onion and sesame seeds, if desired. 